UPPSALA UNIVERSITET

Digital Comprehensive Summaries of Uppsala Dissertations from the Faculty of Pharmacy 298

\title{
Proteomics informed investigation of human hepatocytes and liver tissue
}

NIKLAS HANDIN

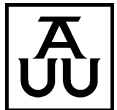

ACTA UNIVERSITATIS UPSALIENSIS UPPSALA
ISSN 1651-6192 
Dissertation presented at Uppsala University to be publicly examined in Room A1:107a, Biomedical center, Husargatan 3, Uppsala, Friday, 10 September 2021 at 09:15 for the degree of Doctor of Philosophy (Faculty of Pharmacy). The examination will be conducted in English. Faculty examiner: Professor Pieter Annaert (Mechanistic Pharmacokinetics KU Leuven, Belgien).

\begin{abstract}
Handin, N. 2021. Proteomics informed investigation of human hepatocytes and liver tissue. Digital Comprehensive Summaries of Uppsala Dissertations from the Faculty of Pharmacy 298. 63 pp. Uppsala: Acta Universitatis Upsaliensis. ISBN 978-91-513-1247-7.
\end{abstract}

A successful drug needs to display beneficial absorption, distribution, metabolism, excretion and toxicity (ADME-Tox) profile. It is therefore important to investigate these properties during the drug discovery process. The liver is of particular interest in ADME-Tox studies, as it is highly metabolically active and oral administrated drugs needs to pass the liver before reaching the systemic circulation. However, a dose of a drug that is efficacious and safe for one individual may be inefficacious or toxic, because of inter-individual variability. Therefore, it is important to investigate the ADME-Tox properties in a sufficiently large population. Investigations on ADME-Tox is usually done in in vitro cell models. Therefore, a variety of models to simulate liver functions have been developed and ranging from subcellular microsomes to complex 3D organoid cultures. This thesis investigates variability of ADME proteins in human liver tissue and in liver cell models.

First, mass spectrometry based targeted proteomics was used to quantify ADME relevant proteins from 149 human liver samples. The observed inter-individual protein variability could not solely be explained by genotype. Therefore, a single transporter protein, the bile and drug transporting protein, NTCP, was investigate in detail. Non-genetic factors, e.g. smoking and alcohol consumption, and epigenetic factors such as DNA methylation, were found to contribute to the observed inter-individual variability of NTCP.

Next, hepatocytes (PHH) were isolated from 54 human livers tissues and after which the hepatocytes where cryopreserved. The variable attachment efficiency of cryopreserved hepatocytes where investigated and an apoptosis inhibition protocol for restoration of attachment properties was developed. This protocol was also successfully applied to 3D cultured PHH spheroids resulting in increased ability to form 3D spheroids.

The effect of culture conditions on the quality of the 3D cultures was also investigated. 3D PHH spheroids were formed and maintained in different, commonly used culture media. The spheroids were characterized by a variety of functional assays including global proteomics. The proteome analysis showed that while no epithelial to mesenchymal transitions was observed, 3D cultures maintained in fasting glucose and insulin levels resembling the in vivo situation showed a more liver-like phenotype with a high expression of ADME proteins and functional cytochrome P450 metabolism. Transporter kinetics were also investigated in the 3D cultured PHH.

Finally, we investigated if global proteomics data from 56 human liver tissues could be deconvoluted to give information about the liver composition. The cell type proportions generated by deconvolution where similar to literature values. Liver samples that displayed deviating cell composition were identified. The deviating liver compositions were in agreement with clinical markers of inflammation in the patient's blood samples and with altered extracellular matrix protein composition, comparable to that found in liver steatosis.

In conclusion, this thesis have investigated variability in ADME proteins in human liver and in in vitro cultures of human hepatocytes, characterized cofounding factors for in vitro cultured hepatocytes and further extended drug disposition studies in 3D cultured hepatocytes.

Keywords: human, liver, hepatocytes, proteomics, cellular stress, apoptosis, hepatotoxicity, 3D culture, spheroid, drug metabolism, drug toxicity, drug transport

Niklas Handin, Department of Pharmacy, Box 580, Uppsala University, SE-75123 Uppsala, Sweden.

(C) Niklas Handin 2021

ISSN 1651-6192

ISBN 978-91-513-1247-7

URN urn:nbn:se:uu:diva-446954 (http://urn.kb.se/resolve?urn=urn:nbn:se:uu:diva-446954) 
All models are wrong, but some are useful.

George E.P. Box 



\section{List of Papers}

This thesis is based on the following papers, which are referred to in the text by their Roman numerals.

I Tremmel, A., van Eijck, B.A.C., Handin, N., Haag, M., Winter, S., Büttner, F., Mazzola, P., Hofmann, U., Klein, K., Hoffmann, P., Nöthen M.M., Gaugaz, F.Z., Artursson, P,. Nies A.T., Schwab, M., Schaeffeler, E. Non-genetic and epigenetic factors contribute to inter-individual variability of the hepatic bile acid and drug transporter NTCP. (Submitted)

II Ölander, M., Wegler, C., Flörkemeier, I., Treyer, A., Handin, N., Pedersen, J.M., Vildhede, A., Mateus, A., LeCluyse, E.L., Urdzik, J., Artursson, P. (2021) Hepatocyte size fractionation allows dissection of human liver zonation. Journal of Cellular Physiology, 236(8):5885-5894

III Ölander, M., Wiśniewski, J.R., Flörkemeier, I., Handin, N., Urdzik, J., Artursson, P. (2019) A simple approach for restoration of differentiation and function in cryopreserved human hepatocytes. Archives of Toxicology, 93(3):819-829

IV Handin, N., Mickols E., Ölander, M, Rudfeldt, J., Blom, K., Nyberg, F., Senkowski, W., Urdzik, J., Maturi, V., Fryknäs, M., Artursson, P. Conditions for maintenance of hepatocyte differentiation and function in 3D spheroid cultures. (Under review)

V Handin, N., Meyer, A., Eriksson, J., Sellin, M., Artursson, P. Transporter kinetics of the organic cation transporter 1 (OCT1) in 3D cultured human hepatocytes (Submitted)

VI Handin, N., Yuan, D., Ölander, M., Wegler, C., Karlsson, C., Jansson-Löfmark, R., Hjelmesæth, J., Åsberg, A., Artursson P. Proteomics-informed deconvolution of different cell types in human liver tissue (Submitted)

Reprints were made with permission from the respective publishers. 
Other contributions

VII Karlgren, M., Simoff, I., Backlund, M., Wegler, C., Keiser, M., Handin, N., Müller, J., Lundquist, P., Jareborg, A.C., Oswald, S., Artursson, P. (2017) A CRISPR-Cas9 Generated MDCK Cell Line Expressing Human MDR1 Without Endogenous Canine MDR1 (cABCB1): An Improved Tool for Drug Efflux Studies. Journal of Pharmaceutical Sciences, 106(9): 29092913

VIII Kundu, S., Ali, M.A., Handin, N., Padhan, N., Larsson, J., Karoutsou, M., Ban, K., Wiśniewski, J.R., Artursson, P., He, L., Hellström, M., Sjöblom, T. (2018) Linking FOXO3, NCOA3, and TCF7L2 to Ras pathway phenotypes through a genome-wide forward genetic screen in human colorectal cancer cells. Genome Medicine, 10(1):2-13

IX Ölander, M., Handin, N., Artursson, P. (2019) Image-Based Quantification of Cell Debris as a Measure of Apoptosis. Analytical Chemistry, 91(9):5548-5552

X Kundu, S., Ali, M.A., Handin, N., Conway, P.L., Rendo, V., Artursson, P., He, L., Globisch, D., Sjöblom, T. Common and mutation specific phenotypes of KRAS and BRAF mutations in colorectal cancer cells revealed by integrative -omics analysis Journal of Experimental \& Clinical Cancer Research. (Accepted)

XI Hellinen, L., Koskela, A., Vattulainen, E., Mikko, L., Wegler, C., Treyer, A., Handin N., Svensson, R., Myöhänen, T., Poso, A., Kaarniranta, K., Artursson P., Urtti, A. Inhibition of prolyl oligopeptidase is a promising pathway to prevent the progression of age-related macular degeneration. (In manuscript) 


\section{Contents}

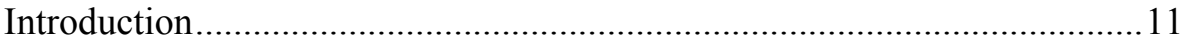

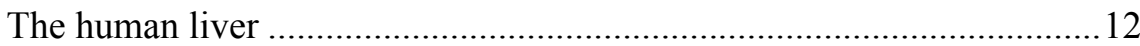

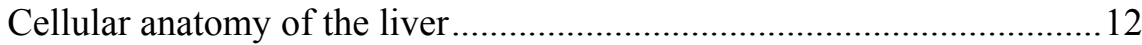

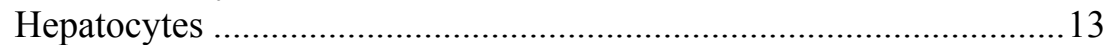

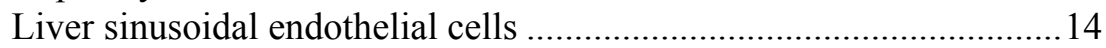

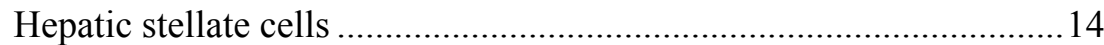

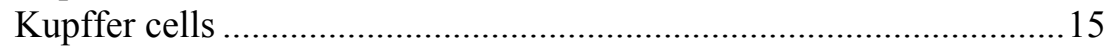

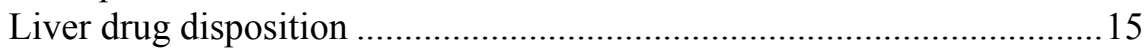

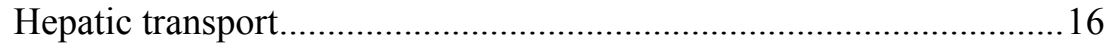

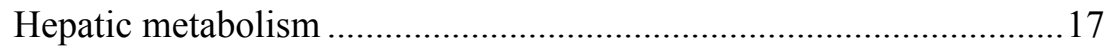

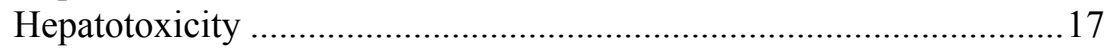

In vitro models for hepatic drug disposition ........................................... 17

Mass spectrometry-based proteomics .....................................................19

Mass spectrometry-based targeted proteomics ……............................20

Mass spectrometry-based global proteomics ......................................21

Bioinformatic analyses of proteomics data ...........................................22

Quantification for proteomics data ................................................22

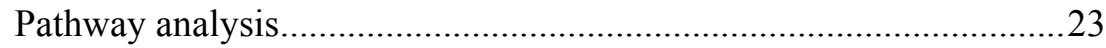

Cellular composition and deconvolution ............................................23

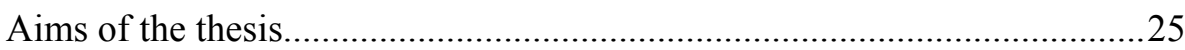

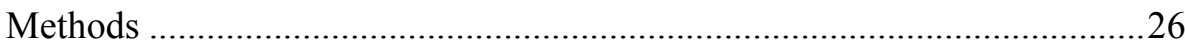

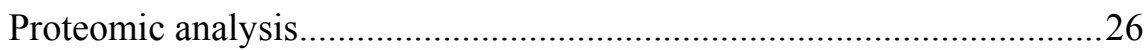

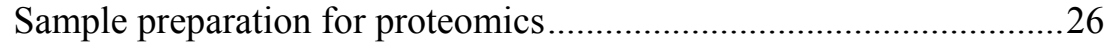

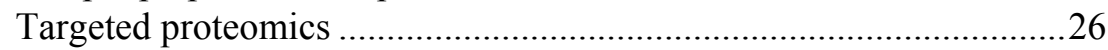

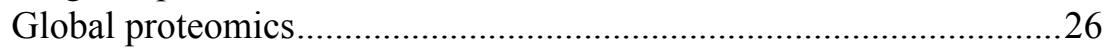

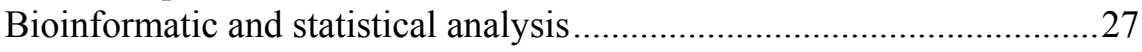

Proteopipe, an automated QC software for LC-MS/MS running

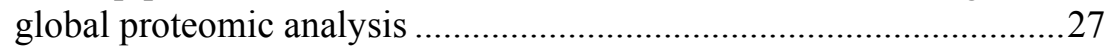

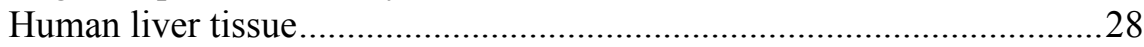

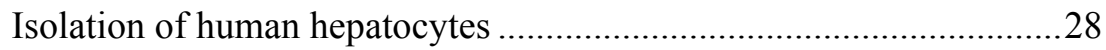

Cryopreservation and thawing of human hepatocytes........................29

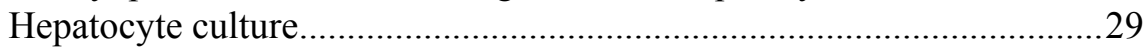

Characterization of hepatocyte culture evaluations ..............................29

Liver-specific gene expression panel and ADME proteins ..................30 


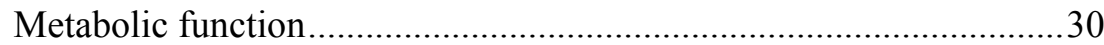

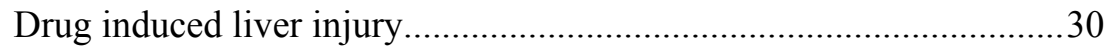

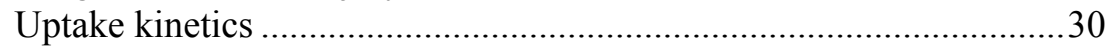

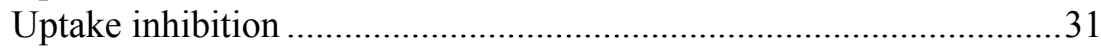

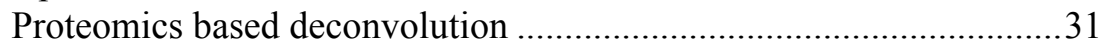

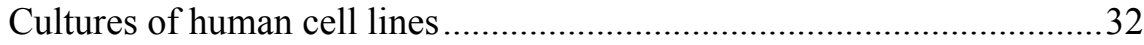

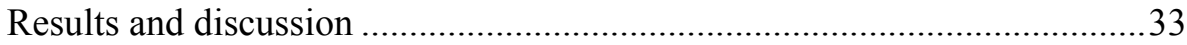

Inter-individual variability of ADME proteins in human liver ..................33

Inter-individual variability of the hepatic bile acid and drug transporter

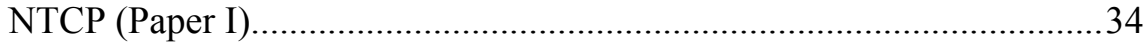

Hepatocyte isolation, characterization and restoration (Papers II-III).....37

Maintenance of hepatocyte differentiation and function in 3D spheroid

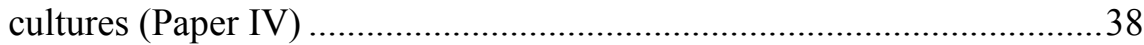

Transporter kinetics in 3D cultured human hepatocytes (Paper V)..........43

Proteomics-informed deconvolution in human liver tissue (Paper VI)....46

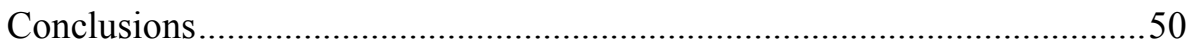

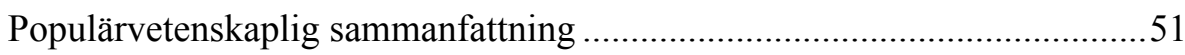

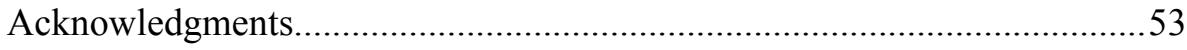

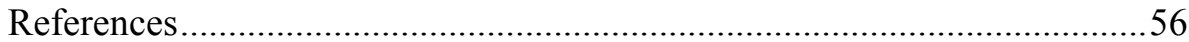




\section{Abbreviations}

2D

3D

$\mathrm{ABC}$

ADME-Tox

ASP+

CRP

CYPs

DDA

DDI

DIA

DILI

DMEM

ECM

FASP

FBS

GUI

GWAS

HBSS

HMM

HSC

iBAQ

IHC

$\mathrm{KC}$

KEGG

LC-MS/MS

LiGEP

LLS

LSEC

LysC

MATEs

MS

NPC

OCTNs

OCTs

PEST

$\mathrm{PHH}$ 2-dimensional

3-dimensional

ATP-binding cassette

Absorption, distribution, metabolism, excretion, and toxicity

4-(4-(dimethylamino)styryl)-n-methylpyridinium

C-reactive protein

Cytochrome P450 family

Data dependent acquisition

Drug-drug interaction

Data independent acquisition

Drug induced liver injury

Dulbecco's Modified Eagle Medium

Extracellular matrix

Filter-assisted sample preparation

Fetal bovine serum

Graphical user interface

Genome wide association study

Hank's Balanced Salt Solution

Hepatocyte maintenance medium

Hepatic stellate cell

Intensity-based absolute quantitation

Immunohistochemistry

Kupffer cell

Kyoto Encyclopedia of Genes and Genomes

Liquid chromatography-tandem mass spectrometry

Liver-specific gene expression panel

Linear least squares

Sinusoidal endothelial cell

Lysyl endopeptidase

Multidrug and toxin extrusion family members

Mass spectrometry

Non-parenchymal cells

Novel organic cation transporters

Organic cation transporters

Penicillin-streptomycin

Primary human hepatocyte 
PPM

ROS

SIL

SLC

TMT

TPA

UGTs
Cellartis Power Primary Hep Medium

Reactive oxygen species

Stable isotopically labelled

Solute carrier

Tandem mass tags

Total protein approach

UDP-glucuronosyltransferases family 


\section{Introduction}

Many factors influence the extent to which a drug can reach systemic circulation and its intended target. For instance, an orally administrated drug needs to be absorbed to reach the systemic circulation. The drug then needs to avoid extensive metabolic clearance and biliary or renal excretion to reach its target at a high enough concentration to be effective. Further, the drug should not have any toxic effect that outweighs its benefits. In particular, drug induced liver injury (DILI) needs to be avoided. In summary, a successful drug needs to display beneficial absorption, distribution, metabolism, excretion, and toxicity (together these five qualities are called ADME-Tox) to be effective.

During the drug discovery process, ADME-Tox properties are investigated in in vitro models that simulate discrete in vivo functions. A variety of in vitro models of liver function have been developed, ranging from subcellular microsomes, for studies of drug metabolism only, to cultured liver cells in various configurations ranging from simple monolayers to complex 3D structures for studies of drug metabolism, transport and DILI. These various culture configurations come with different levels of similarity to in vivo conditions, reproducibility, throughput, and cost. ${ }^{1}$

Often, the cultured liver cells used in these studies originate from small animal species such as rodents, but to avoid species differences, it is preferable to use human liver cells. A complication associated with human liver cells is inter-individual variability, which originates from differences in both genetic and environmental backgrounds. It is important to understand how inter-individual variability relates to liver cell composition and function.

In this thesis, quantification of protein expression is used to investigate inter-individual differences in human livers and in isolated human hepatocytes cultivated in 2D and 3D configurations. Mass spectrometry-based proteomics is used because this technique enables quantification of thousands of proteins, which is close to the total proteome. ${ }^{2}$ Special focus is given to ADME-Tox proteins, specifically, enzymes responsible for drug transport and drug metabolism, both of which influence drug disposition. ${ }^{3}$ Global protein profiles are used to optimize cell culture conditions and modify media with the aim of obtaining liver cell cultures with functions close to those of the human liver. Deconvolution of the global liver proteome is used to investigate the variability of individual liver cells, and examples of how these differences correlate with disease markers will be presented. 


\section{The human liver}

The largest visceral organ in the human body is the liver. The liver has an average weight of $1500 \mathrm{~g}$ and receives about a quarter of the total cardiac output. ${ }^{4}$ About 70 to $80 \%$ of the liver's blood is supplied trough the portal vein and the rest is supplied by the hepatic artery. The blood from the hepatic artery is rich in oxygen and the blood from the portal vein is rich in nutrients that have been taken up by the digestive system. Compounds absorbed in the digestive system need to pass through liver before reaching systemic circulation, a process called hepatic first passage. Because one of the liver's main functions is detoxification and elimination of xenobiotics, many drugs are substantially metabolized during hepatic first passage. ${ }^{5}$ The liver is also the biggest gland in the human body, producing and secreting bile components and many blood proteins like albumin. ${ }^{6}$

\section{Cellular anatomy of the liver}

The liver primarily consists of parenchymal hepatocytes, which comprise about $80 \%$ of the liver volume. ${ }^{7,8}$ The liver also contains non-parenchymal cells (NPCs) such as liver sinusoidal endothelial cells (LSECs), liver-specific macrophages called Kupffer cells (KCs), and hepatic stellate cells (HSCs). NPCs constitute about $6.5 \%$ of the liver volume. LSECs are the most abundant non-parenchymal cell type followed by KCs and HSCs. ${ }^{7,8}$

LSEC form vessels from the portal vein and hepatic artery to the central vein called sinusoids in which blood flows and $\mathrm{KC}$ travel. Between these vessels and hepatocytes is the perisinusoidal space (space of Disse) where HSC are found. Together with bile ducts, these linear structures are organized in repeating hexagonal structures called lobules (Figure 1). Each corner of the hexagonal lobule consists of the portal triad comprising bile ducts, portal vein and hepatic artery, and in the centre is the central vein. ${ }^{9}$ 


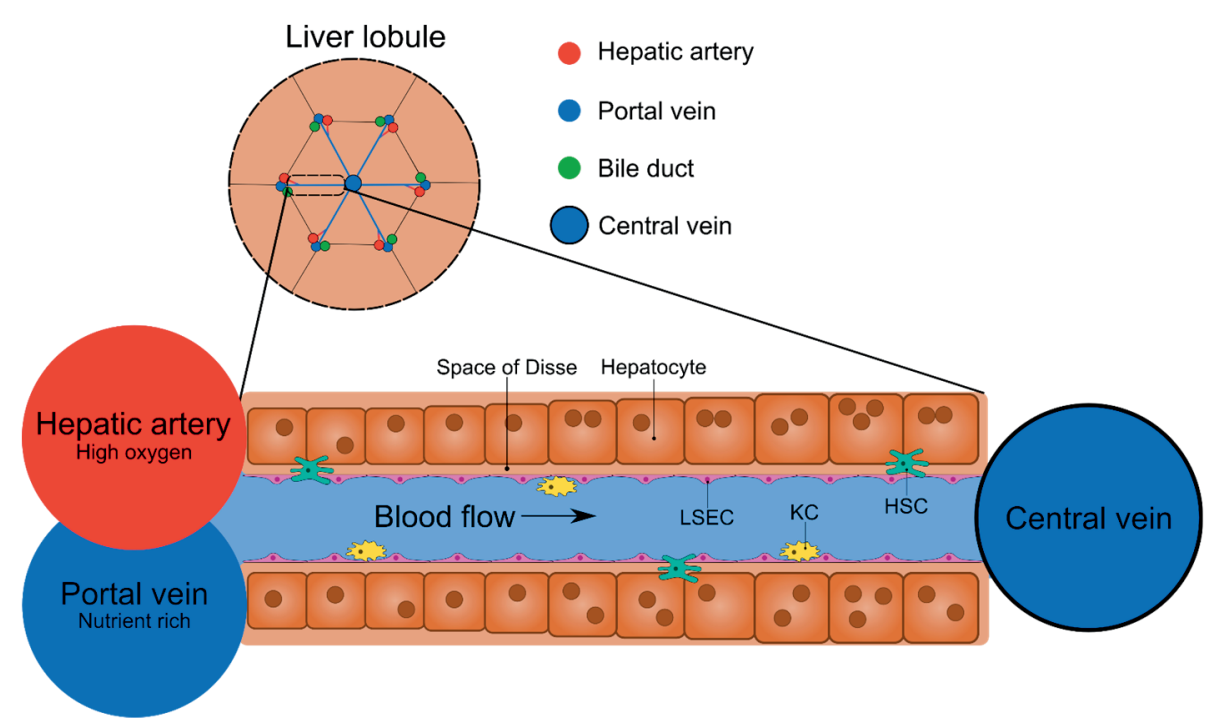

Figure 1. Schematic of the microarchitecture of the liver. The liver is organized in units called lobules. Lobules are hexagonal units and at each corner of the hexagon is a portal triad consisting of a hepatic artery, a portal vein, and a bile duct. Blood flows from these corners to the centre of the hexagon where a central vein is located. Liver sinusoidal endothelial cells (LSECs) line the vessels spanning the corners and the centre of the hexagon, allowing hepatocytes access to blood constituents. Kupffer cells (KCs) adhere to the surface of LSECs and hepatic stellate cells (HSCs) residing in the spaces between LSEC and hepatocytes (the space of Disse).

\section{Hepatocytes}

Hepatocytes, which make up the majority of the liver, are specialized epithelial cells responsible for most liver functions, such as metabolic, secretory, and endocrine functions. ${ }^{8,9}$ Therefore, primary human hepatocytes (PHHs) have been used extensively for in vitro studies of liver functions, including drug transport, metabolism, and toxicity studies.

Hepatocytes' spatial heterogeneity following the blood flow from the portal triad to the central vein is called zonation. ${ }^{10}$ Hepatocytes along the zonation gradient differ in, e.g., cell size, ploidy, and metabolic activity. ${ }^{10,11}$ The size of hepatocytes ranges from $18 \mu \mathrm{m}$ in the periportal zone to more than $30 \mu \mathrm{m}$ in the perivenous zone, with ploidy number increasing with cell size (Figure 1). ${ }^{11,12}$ Many metabolic processes, such as carbohydrate and nitrogen metabolism, differ between zones. Periportal hepatocytes mainly perform gluconeogenesis and urea synthesis. Conversely, pericentral hepatocytes primarily perform glycolysis and glutamine synthesis ${ }^{10,13}$, as this is where the majority of drug metabolising enzymes are more highly expressed. ${ }^{14,15}$ Worth noting is that the extent of these processes gradually change along the porto-central axis and none of the processes are completely abolished at either side. 
Hepatic zonation has been known for a long time, but the underlying regulatory pathways are neither yet fully understood nor elucidated. The oxygen gradient is, together with the hedgehog pathway and $\beta$-catenin signalling, considered curcial in creating hepatocyte zonation. ${ }^{16-18}$ However, both the hedgehog pathway and $\beta$-catenin signalling can be modulated by the hypoxia signalling system, and the dynamic interplay among all these pathways can be seen as the driver of hepatic zonation. ${ }^{10}$

Hepatocytes in traditional 2D in vitro cultures dedifferentiate, lose their function, and do not survive for long (only a few days). ${ }^{19-21}$ To mitigate these problems, cultures allowing for cell-matrix or cell-cell contact in all three dimensions have been used. ${ }^{22-24} 3 \mathrm{D}$ cultures have recently gained popularity and show increased function and survival compared to traditional 2D cultures.

\section{Liver sinusoidal endothelial cells}

In the lobule, LSECs form the vessels from the portal vein and hepatic artery to the central vein. These thin and elongated cells are highly specialized endothelial cells. LSECs have many small pores, or fenestrations, with diameters from 100 to $170 \mathrm{~nm}^{25,26}$ These fenestrations work as a sieve and facilitate the transfer of substrates between the blood and hepatocytes. LSECs are also effective scavengers of waste macromolecules and have a greater endocytic capacity compared to other endothelial cells. ${ }^{26}$ The internalised ligands are transported to and efficiently degraded in lysosomal compartments. LSECs have an overall anaerobic metabolism with few mitochondria per cell, producing lactate, which is then taken up by hepatocytes. ${ }^{27,28}$

\section{Hepatic stellate cells}

HSCs are the liver pericytes and reside in the space of Disse between hepatocytes and LSECs. An HSC has a dendrite-like morphology with micro-projections that stretch from LSECs to hepatocytes. ${ }^{29}$ The most characteristic function of HSCs is their role in transporting and storing vitamin A (retinol). About $80 \%$ of total body retinol is stored within HSCs in lipid droplets. ${ }^{29}$ Another important function of HSCs are their role in vasoregulation using a large number of receptors and intracellular mediators that modulate cellular contraction. HSCs are also important in liver architecture, as they regulate the extracellular matrix (ECM) by secreting ECM molecules and ECM-degrading enzymes. ${ }^{29}$

In cellular injury or with inflammation, HSCs can leave their quiescent state and begin producing a surplus of ECM. This surplus ECM can lead to fibrogenesis, which, if maintained, leads to the potentially lethal condition of liver cirrhosis. In cirrhosis, normal cellular function is disrupted and eventually causes liver failure and liver cancer ${ }^{30}$ Cirrhosis is estimated to affect between $1 \%$ and $2 \%$ of the global population, with over 1 million deaths annually worldwide. ${ }^{30}$ 


\section{Kupffer cells}

KCs are liver-specific macrophages that constitute $80-90 \%$ of all macrophages in the human body. ${ }^{31} \mathrm{KCs}$ encounter material arriving via the gastrointestinal tract, including food antigens and microorganism-derived products. This strategic location gives KCs an important role in immune surveillance and in initiating a wider immune response, recruiting other immune cells from the blood if needed..$^{32}$ Furthermore, they are important in capturing and eliminating blood-borne pathogens. ${ }^{33,34}$

$\mathrm{KCs}$ and recruited macrophages are also involved in fibrosis by keeping the number of activated HSCs elevated and promoting HSC migration. ${ }^{35} \mathrm{How}-$ ever, they have a divergent function in fibrogenesis and may mitigate fibrosis through extracellular matrix degradation and killing of activated HSC by expression of TNF-related apoptosis-inducing ligand. ${ }^{36,37}$

\section{Liver drug disposition}

Once a drug reaches the liver, it can enter the cells by passive lipoidal diffusion or via a transport protein. Inside the cells, the drug can be metabolized. The drug as well as its metabolite(s) can then be transported out of the cell, either into systemic circulation or into the bile, involving both drug transport and metabolizing enzymes (Figure 2). It is therefore essential to study these proteins to understand drug disposition mechanisms. Furthermore, drugs that interact with the same transport protein or metabolizing enzyme can result in an altered drug disposition. Such drug-drug interactions (DDIs) could cause a drug to lose its effectiveness or to elicit side effects. ${ }^{38}$ 


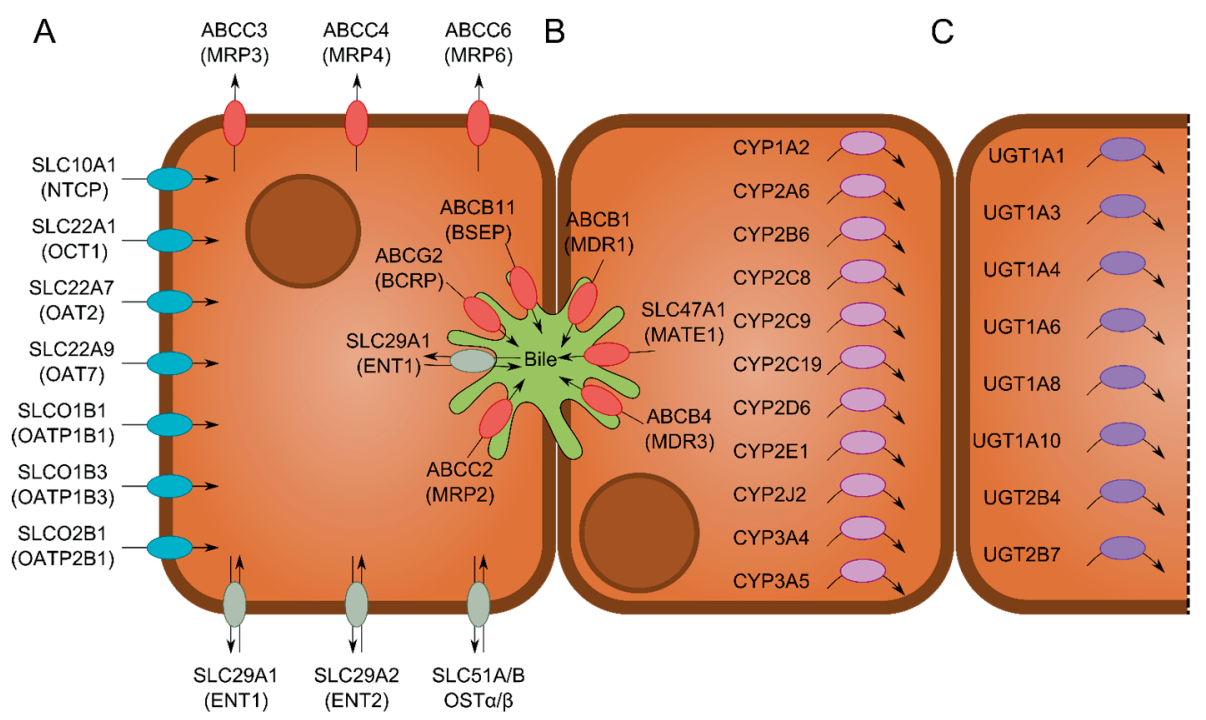

Figure 2. Transporters and metabolizing enzymes important for hepatic drug disposition. A, SLC and ABC superfamily transport proteins. ${ }^{39} \mathbf{B}$, Cytochrome P450 proteins. ${ }^{40} \mathbf{C}$, UDP glucuronosyltransferase proteins. ${ }^{41}$

\section{Hepatic transport}

Drugs can pass through the cell membrane by lipoidal diffusion and move along the chemical potential gradient, which is usually from a high to a low drug concentration. Diffusion can also be facilitated by proteins at the plasma membrane working as channels, which circumvents the need to directly interact with the plasma membrane. ${ }^{42}$ Passive diffusion does not require any energy, as it is driven by the chemical potential.

In addition to passive transport, drugs can be actively transported by energy-demanding processes. Active transport is carried out by transport proteins both into the cell (uptake) and out of the cell (efflux) ${ }^{43}$ Transport proteins can increase permeation through uptake processes or limit permeation through efflux. In hepatic transport, drugs can also be eliminated by secretion into the bile (Figure 2A).

The transporters in humans belong to two major superfamilies, namely the solute carrier (SLC) superfamily comprising 395 members and the ATP-binding cassette (ABC) superfamily comprising 49 members. ${ }^{44,45}$ The majority of drug-transporting SLCs are uptake transporters and do not rely directly on energy from ATP. In contrast, as their name implies, ABC transporters are ATPdriven. ${ }^{43}$ These transporters are heterogeneously expressed in different organs and between individuals. ${ }^{46,47}$ For that reason, different panels of liver-specific transporters have been suggested for studying hepatic drug transport. ${ }^{39,48}$ 


\section{Hepatic metabolism}

Inside hepatocytes, drugs can be metabolized, usually to increase their elimination. ${ }^{49,50}$ Drug metabolism can be divided into two phases. In phase I, metabolic enzymes modify the drug, usually by hydroxylation. ${ }^{51}$ Most phase I metabolism is performed by the cytochrome P450 family (CYPs). In phase II, enzymes either conjugate charged species (like glucuronic acid) directly to a drug molecule or to its phase I metabolite. ${ }^{51}$ Most phase II metabolism is performed by the UDP-glucuronosyltransferase family (UGTs) (Figure 2B-C).

\section{Hepatotoxicity}

Due to the liver's location and central role in drug metabolism and elimination, the liver is at a large risk of coming into contact with toxic compounds and/or metabolites. ${ }^{52}$ As a result, one of the most common reasons for a drug to be withdrawn from the market is drug-induced liver injury (DILI). ${ }^{52,53}$ Two examples of DILI mechanisms are increased accumulation of reactive oxygen species (ROS) and obstruction of bile acid homeostasis. ${ }^{54}$ Both cause cellular stress, leading to apoptosis activation or necrosis, resulting in cell death. More difficult DILIs to study are so-called 'idiosyncratic' DILIs, where a mixture of characteristics is observed that are not clearly related to dose, route, or duration of drug administration. ${ }^{55}$ It is plausible that many idiosyncratic DILI cases are caused by inadvertent activation of the adaptive immune response, which could be caused by "danger" signals produced by minor damage done by the drug or drug-protein complex. ${ }^{55}$

\section{In vitro models for hepatic drug disposition}

Hepatocytes isolated from human liver tissue are currently considered the gold standard for in vitro study of key elements of drug disposition, which are needed for a successful drug development process. ${ }^{56,57}$ However, the several different culture configurations possible for $\mathrm{PHH}$ cultures have various advantages and shortcomings. The choice of culture configuration depends on the research question, facilitated by considerations such as throughput, cost, reproducibility, and culture time. A few different culture configurations are described below (Figure 3).

Extensive research has investigated the applicability of cryopreserved hepatocytes. ${ }^{58,59}$ Being stored frozen, they have the advantage of being available on demand. However, batch quality can vary considerably after thawing, and further improvements to the technique are needed. ${ }^{60,61}$

When cultured in standard configurations in vitro, hepatocytes are subject to, e.g., loss of function, dedifferentiation, and loss of viability. ${ }^{19-21}$ To miti- 
gate some of these problems, cultures allowing hepatocytes to form cell-matrix or cell-cell connections in all three dimensions (which better resembles in vivo conditions) have been used. ${ }^{22-24}$ These cultures retain their in vivo characteristics for a longer period of time than simple monolayer cultures. For example, 2D monolayers in which hepatocytes are cultured on an ECM surface dedifferentiate in a few days. However, when a second ECM layer is added on top of the monolayer (in a configuration called a sandwich culture), hepatocytes both retain many differentiated features for a longer space of time and remain polarized, even forming small, but closed biliary compartments. ${ }^{1,62}$

Longer-term maintenance of a differentiated phenotype is possible in threedimensional (3D) cultures such as hepatocyte spheroids. ${ }^{22}$ PHH spheroids self-aggregate into spheroidal structures if they cannot attach to anything else, for example, if they are in hanging drops or low-attachment surfaces. ${ }^{23,63,64}$ Hepatocytes will also start to deposit their own ECM and encapsulate the formed structure ${ }^{65} \mathrm{PHH}$ cultured in this formation are functionally active for several weeks and closely resemble their in vivo phenotype. ${ }^{23,66}$ Mimicry of the liver can be enhanced even further (at the expense of throughput) by introducing medium flow in liver on-chip cultures. ${ }^{1}$

Several different culture media have been used for hepatocyte cultures, ranging from a well-defined medium created in 1971 (called Williams E) to optimized, presumably more advanced commercial media. ${ }^{19,23,67-69}$ However, the high levels of glucose and insulin used in many hepatocyte cultures could be suboptimal for maintenance of in vivo-like hepatocyte phenotypes. ${ }^{70-72}$ 


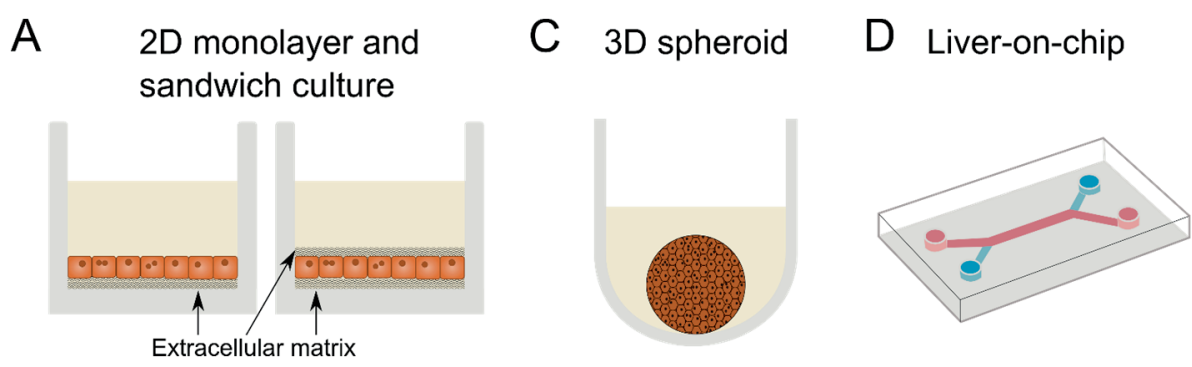

Figure 3. Examples of different configurations of in vitro models of PHH for hepatic drug disposition studies. A, 2D cultures in which hepatocytes are cultured on a surface of ECM proteins. A monolayer culture of hepatocytes is overlaid on a surface of ECM. If a second layer is added on top of the cells, a sandwich culture is obtained. B, 3D spheroid cultures are formed when hepatocytes self-aggregate and form small spherical structures. C, 3D liver-on-chip cultures are 3D cultures with microfluidics that simulate tissue perfusion in vivo. The microfluidics allow for creation of nutrient and oxygen gradients similar to those in liver lobules (outlined in Figure 1).

\section{Mass spectrometry-based proteomics}

Mass spectrometry (MS) is an analytical method used to detect and quantify ionized molecules. MS uses electromagnetic fields to separate and guide ionized molecules to a detector, where they can be measured. The first quadrupole mass filter was invented 1953 and this type of filter is still a fundamental part in many MS instruments. ${ }^{73}$ A quadrupole determines which ionized molecules should be selected and guided forward, which is especially useful when the charge and molecular weight is known, e.g. in targeted proteomics approaches with a few molecules of interest.

Substantial progress in MS was achieved in 2005 when the first orbitrapbased MS was described and made available. ${ }^{74}$ As the name suggests, in orbitrap MS, ionized molecules enter the orbitrap and are trapped in an orbit around the central electrode. The oscillations of the molecules depend on their mass and charge, and a mass spectrum can be generated using Fourier transformation.

Orbitraps avoid the complexity and size of Fourier transformation ion cyclotron resonance analysers, the low sensitivity and dynamic range of orthogonal time-of-flight analysers, and the limited mass accuracy of ion trap analysers. ${ }^{74}$ These benefits place them among the most prominent instrumentation in mass spectrometry. Another benefit of the orbitrap method is that it can detect many different species of molecules at the same time, in a broad dynamic range, which is essential for global proteomics where the aim is to measure all species. 
MS-based proteomics can be divided into two categories, top-down and bottom-up. Top-down approaches are used to study intact proteins, and bottom-up approaches are used to study peptide fragments of proteins. For quantitative proteomics analysis, bottom-up approaches are more commonly applied because they offer better initial separation of the small peptides and higher sensitivity than the intact proteins in top-down approaches.$^{75}$ However, with the bottom-up approaches, there is a need to identify the sequences and the protein origin for each of the large number of peptides generated by protein digests.

To perform bottom-up MS based proteomics, protein is extracted and digested. Extracting protein from cells and tissues can be done using mechanical means such as high pressure, sonication, and bead beaters. ${ }^{76}$ Reagent-based methods using denaturants or detergents, such as urea, sodium dodecyl sulphate, and Triton X-100, can also be used to lyse cells and solubilize proteins. ${ }^{77}$ However, many detergents are incompatible with MS, as they cause ion suppression. ${ }^{78}$ Detergents and salts that cause ion suppression and similar problems can be removed by clean-up methods like gel electrophoresis, protein precipitation, and filter-assisted sample preparation (FASP). ${ }^{77}$

In FASP, solubilised proteins are retained on a filter, and salts, buffers, and detergents are washed through the filter using a highly concentrated urea buffer. ${ }^{79}$ Proteins on the filters are then alkylated and digested into peptides that are small enough to pass through the filter. Two digestion enzymes commonly used in this technique are lysyl endopeptidase (LysC) and trypsin. LysC cleaves the proteins after a lysine residue, and trypsin cleaves peptides after lysine and arginine residues. As a result of enzymatic cleavage, the peptides receive a C-terminus positive charge, which is beneficial for MS analysis. Resulting peptides are also easily further fragmented via MS. ${ }^{80-82}$ To increase digestion efficiency as well as decrease sample complexity, sequential digestion is often performed. ${ }^{83,84}$ Other ways of reducing sample complexity to increase proteome coverage is to perform fractionation, such as high $\mathrm{pH}$ fractionation and isoelectric focusing. ${ }^{85,86}$

\section{Mass spectrometry-based targeted proteomics}

In targeted proteomics, only a subset of all proteins are of interest. Typically, peptides from the desired proteins are selected and these surrogate peptides are then used for quantification. The selection of surrogate peptides should account for many aspects such as MS suitability (depending on chemical properties), uniqueness to the protein, and the probability of enzymatic cleavage. ${ }^{87}$ Properly selected surrogate peptides will then ensure accurate quantification.

A stable isotopically labelled (SIL) version of the surrogate peptide is often used as an internal standard, helping to identify the correct peaks and to accurately calibrate the sample. The SIL peptide can be introduced prior to analy- 
sis, added as part of a longer protein, or added in form of concatenated peptides. If a SIL peptide is part of a protein or concatenated peptide, it is added to the sample before the protein digestion step so that the peptides will be released during digestion. The benefit of this procedure is the internal standard reflecting variability in digestion efficiency. ${ }^{88}$

The benefit of targeted proteomics is that only a limited number of targeted proteins are analysed. Therefore, run times are shorter compared to global proteomics. The short run time is beneficial for routine measurements of a specific subsets of proteins of interest, e.g. for predictive pharmacokinetics. ${ }^{47,89,90}$ However, only information about the specific proteins of interest is obtained.

\section{Mass spectrometry-based global proteomics}

In contrast to targeted proteomics, which considers only a subset of proteins, global proteomics aims to analyse the entire proteome: with this technique, several thousands of proteins are measured at the same time. ${ }^{91}$ Naturally, run times for global proteomics are longer than for targeted proteomics. However, in global proteomics, surrogate peptides are not necessarily needed as standards, and label-free approaches are commonly used. Label-free methods have not been thought to provide as accurate of quantification as labelled peptide standards. ${ }^{92}$ However, improvements in sample preparation, instrumentation, and data processing now allow label-free quantification with accuracy similar to that found in labelled peptide standards ${ }^{93}$ Global proteomics can be divided into two types: data dependent acquisition (DDA), and data independent acquisition (DIA).

In DDA, the acquisition method uses the data to decide what to do. An example is the Top-N method, where the highest peaks are chosen for analysis in every cycle. The benefit of DDA is that the method utilizes the data generated and adjusts itself accordingly, with no time wasted on entities not present in the current sample. However, the drawback is that DDA has assumptions and biases. For the Top-N method, entities with smaller peaks will not be recovered.

In DIA, the acquisition method is independent of the acquired data. One way data are acquired is by utilizing fragmentation windows of a fixed size. Everything within a given mass-to-charge window will be fragmented. The advantage of DIA is that it treats every sample in the same way, and DIA is therefore unbiased. The disadvantage is that analysis is computationally complex, often requiring a peptide library unique to each analysis setup. ${ }^{94}$ 


\section{Bioinformatic analyses of proteomics data}

With both targeted and global proteomics, bioinformatic analyses are required to recover sequences, quantify protein abundances, and provide biological interpretations of the data. In targeted proteomics, major analyses are performed prior to practical experimentation when searching for appropriate surrogate peptides. These peptides should be evaluated based on the following criteria: uniqueness, chemical properties, posttranslational modifications, and possible polymorphisms. ${ }^{87}$ The bulk of bioinformatics in global proteomics comes after data acquisition, the point being to give a biological meaning to the thousands of quantified proteins.

\section{Quantification for proteomics data}

Quantification of proteomics data can be done in several different ways. In targeted proteomics, usually the fraction of the surrogate peptide in different dilutions and the SIL version of the peptide are quantified. In global proteomics, relative quantification methods using different types of labelling techniques and label-free techniques are used.

For isobaric labelling, e.g., tandem mass tags (TMT), an isobaric tag is attached to the peptides and samples are then pooled together. Because the tags are isobaric, there is no increase in sample complexity. When analysed, the isobaric tag is cleaved and reporter ions of different sizes, corresponding to the different pooled samples, are measured and quantified. Hence, relative signals between the multiplexed samples are obtained.

For label-free techniques, e.g. intensity-based absolute quantitation (iBAQ) or a total protein approach (TPA), no labels are added and quantification is done using the peptide intensities. In the iBAQ method, the peptide intensities for the proteins are summed and divided by the number of theoretically possible peptides. This procedure is similar to mRNA sequencing, where the signal is often divided by transcript length. In TPA, the assumption is made that the sum of all peptide intensities corresponds to the total protein content. ${ }^{83}$ Under this assumption, the concentration of a protein is calculated by dividing its summed peptide intensity by the sum of all peptides times molecular weight according to the formula:

$$
\text { Protein concentration }=\frac{\mathrm{MS} \text { signal }}{\text { Total } \mathrm{MS} \text { signal } \times \mathrm{M}_{\mathrm{W}}}
$$

where "MS signal" is the sum of the intensities from the specific protein, "Total MS signal" is the sum of all intensities in the sample, and " $\mathrm{M}_{\mathrm{w}}$ " is the molecular weight of the protein. 


\section{Pathway analysis}

As mentioned above, bottom-up global proteomics generates a large amount of data. However, the relative abundances of particular proteins do not necessarily reflect the complex biological networks involved in phenotypic changes (like changes resulting from disease) in the study of interest. ${ }^{95}$ Here, pathway analysis can facilitate interpretation of the proteomics dataset by helping to generate hypotheses, which in turn will eventually lead to biologically meaningful conclusions. ${ }^{95}$

One way of performing pathway analysis is to do an over-representation analysis. ${ }^{96}$ In short, this method compares an altered set of proteins, e.g. a number of differentially expressed proteins, with a set of functional joint proteins, e.g. a specific biological pathway. The dataset is then tested to see whether more proteins belonging to this pathway are found than we would expect by random chance.

Another way of performing pathway analysis is by functional class scoring. ${ }^{96}$ Instead of looking at a subset of proteins as per over-representation analysis, all measured proteins are used. The proteins are ranked, for example using fold change, and the relative positions of functional joint proteins in the ranked protein set can then be tested.

It is also important to consider what biological knowledge base should be utilized in the pathway analysis. There are several databases built on quite different biological knowledge sets, which would cause the same data to be interpreted in different ways. A few examples of such databases are Reactome ${ }^{97}$ (which collects interactions of molecules to form a network), the Kyoto Encyclopedia of Genes and Genomes (KEGG) ${ }^{98}$ (which has diagrams of interaction and relation networks), PANTHER ${ }^{99}$ (which classifies proteins according to their evolution, function, and biological process), and Go Consortium $^{100}$ (which defines concepts to describe gene function). The results of successful pathway analyses are condensed lists of relevant pathways.

\section{Cellular composition and deconvolution}

Tissue samples are complex mixtures of different cell types and extracellular compartments. In the human body, more than 200 distinct cell types have been identified by single-cell sequencing. ${ }^{101,102}$ Tissue samples are routinely used in clinical medicine and biological research, and because a tissue is made of both cellular and extracellular components, variations in cellular and extracellular proportions will influence data interpretation. For example, an inflammatory process often increases the number of immune cells, and in fibrosis, the extracellular compartment will increase at the expense of cellular content.

To account for cellular variation in samples, various deconvolution algorithms for transcriptomic data have been developed. Transcriptome-based de- 
convolution has been successfully applied in several studies, e.g., in investigating the infiltration of lymphocytes in tumours ${ }^{103,104}$ and in predicting recurrences in breast cancer. ${ }^{105}$

Deconvolution of cellular composition can be done in several different ways, but all these methods can be divided into two main groups, namely partial and complete deconvolution. Partial deconvolution tries to solve and find either cellular composition or cellular expression, which is why the respective other value needs to be determined experimentally. Cellular expression can be measured with, e.g., single-cell transcriptomics. Complete deconvolution tries to solve and find both cellular composition and cellular expression without data input for either value.

Investigating cellular composition through deconvolution of proteomic data is more difficult to perform. One problem is that single-cell proteomics lack the necessary depth and resolution. The technique of global proteomics is also relatively new and rapidly evolving, so access to data of sufficient depth and quality for comparison is limited. In addition, the number of proteins obtained through global proteomics is generally smaller than the number of transcripts obtained by RNA sequencing methods. ${ }^{106,107}$ 


\section{Aims of the thesis}

The overall aim of this thesis was to use mass spectrometry-based proteomics and functional studies to better understand variability in the liver and in in vitro models used to study liver function, with a specific emphasis on drug transporting proteins and metabolising enzymes.

The specific aims were:

- To develop and apply targeted proteomics to quantify transporter expression in a collection of human liver samples and to use the protein expression of the bile acid and drug transporter, NTCP (sodium-dependent taurocholate co-transporting polypeptide), to investigate the underlying mechanisms of inter-individual variability using a multi-omics approach (Paper I).

- To isolate primary human hepatocytes and characterize variability in size and size-dependent differences in the proteomes and drug metabolism of batches of cryopreserved hepatocytes. (Paper II).

- To examine the batch variability observed in the ability of cryopreserved hepatocytes to form 2D monolayers and 3D cultures, with the goal of improving the performance of suboptimal batches (Paper III).

- To characterize the variability observed in 3D cultured human hepatocyte spheroids and to develop improved 3D spheroid culture conditions (Paper IV).

- To investigate the kinetics of a model transporter substrate in 3D cultures of human hepatocytes (Paper V).

- To investigate whether global proteomics data from a collection of human liver samples can be used to deconvolute cell type composition in human liver tissues, and if so, to characterize inter-individual variability in liver cell composition (Paper VI). 


\section{Methods}

\section{Proteomic analysis}

In Papers I-VI, the proteome of human liver tissues, isolated hepatocytes, primary cells, and cell lines were analysed. Bottom-up proteomics was used in which proteins from the samples were extracted and digested to peptides. For Paper I, targeted proteomics was used and for Papers II-VI, global proteomics was used.

\section{Sample preparation for proteomics}

Samples were lysed in a mixture of DTT and SDS in $100 \mathrm{mM}$ Tris $/ \mathrm{HCl}$, heated to denature the proteins, sonicated with a Branson rod-type sonicator to further solubilize proteins and shred DNA strands, and clarified by centrifugation. The lysates were then processed using the FASP or the MED-FASP protocol using either trypsin only or LysC followed by trypsin.

\section{Targeted proteomics}

Bottom-up targeted proteomics was performed in Paper I using the FASP protocol and trypsin as digestion enzyme. The resulting digests were subjected to LC-MS/MS using a triple quadrupole instrument (Sciex QTRAP 6500) set to scheduled multiple reaction monitoring with transitions corresponding to the selected peptides. The proteins of interest were quantified using three transitions of peak areas of the surrogate peptide standard, divided by the corresponding internal standard SIL peptide. Integration of the peaks was done using MultiQuant software.

\section{Global proteomics}

Global bottom-up proteomics was performed in Papers II-VI using the MEDFASP protocol with LysC followed by trypsin to prepare samples for LCMS/MS. The samples were analysed on a high-resolution orbitrap (Q Exactive) mass spectrometer. The machine was set to a Top-N method. Proteins were identified using MaxQuant software ${ }^{108}$ with the human reference proteome from UniProt (accession number: UP000005640) as the search database, 
and the reversed database was used as a decoy database for quantifying false matches. TPA was used as the quantification method.

\section{Bioinformatic and statistical analysis}

Bioinformatics and statistical analyses were performed in all papers using the appropriate subset of the following software. Global proteomics data was handled in Microsoft Excel, R, or Perseus. ${ }^{109}$ For statistical hypotheses testing, R, Perseus, or GraphPad Prism were used. Differentially expressed proteins in proteomics data were investigated using a t-test with permutation-based FDR calculation in Perseus. Statistical enrichment analysis and functional annotation clustering were done using PANTHER ${ }^{110}$ and David. ${ }^{111}$ Mathematic operations that required programming, e.g. optimization algorithms and in silico mixing, were done using Matlab R2019B and in R. Images were analysed using Image.${ }^{112}$

For protein sequences, the UniProt references were used. ${ }^{113}$ For annotation purposes such as subcellular location, cell-type specific expression, and tissue expression, several databases were used including UniProt, the Human Protein Atlas, and a single-cell RNA sequencing database. ${ }^{15,113,114}$

\section{Proteopipe, an automated QC software for LC-MS/MS running global proteomic analysis}

Proteopipe, an automated pipeline to assess the performance of the instruments used for global proteomics, was written in R. The pipeline utilized and built upon PTXQC ${ }^{115}$, MaxQuant ${ }^{108}$ and proteowizard. ${ }^{116}$ A graphical user interface (GUI) was built to easily visualise whether an acceptable performance was achieved (Figure 4A) and to easily and simultaneously visualise the performance of all QCs performed over one year. All data produced by the pipeline is saved and stored. 
A

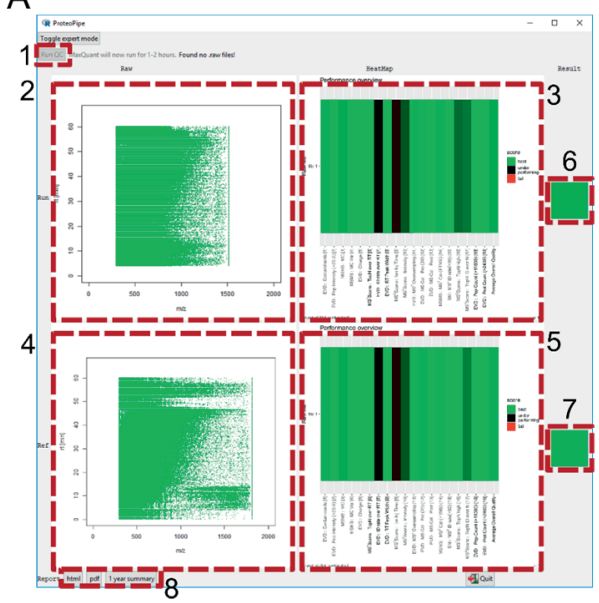

B

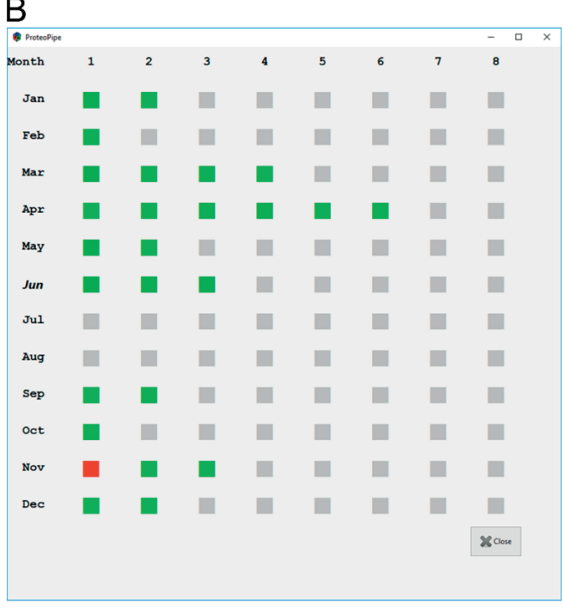

Figure 4. Graphical user interface of the Proteopipe software developed for QC of global proteomics instruments. A, 1. To start the program, the file from the instrument is placed in the Proteopipe folder and this button is pressed. 2. After loading the input file, a chromatogram of the run is shown. 3. Several different aspects from sample prep to mass spectrometry performance are visualized, ranging from good (green) to bad (red) with an intermediate (black). 4. A chromatogram of a previous run that that has passed quality control can be used as a reference. 5. An evaluation of the reference run in 4 for comparison with the current run. 6. Overall QC results. 7. Overall results of the reference run in 4 . B, Visualization of the overall performance on all QCs runs over a one-year period.

\section{Human liver tissue}

Papers II-V used human liver tissue obtained from cancer patients undergoing liver resection surgery at Uppsala University Hospital (Akademiska sjukhuset). The tissue obtained is surplus liver tissue and histologically normal. All donors signed an informed consent approved by the Uppsala Regional Ethical Review Board (Ethical approval no. 2009/028 and amendment 2019/1108).

\section{Isolation of human hepatocytes}

In Papers II-V, human hepatocytes were isolated using a slightly modified two-step collagenase perfusion procedure described previously ${ }^{117}$. In brief, excessive blood was rinsed from liver tissue with Hypothermosol FRS (Biolife Solutions) before transport to the laboratory. Two blood vessels were cannulated and perfused with collagenase and protease buffers while submerged in DPBS. The resulting cell suspension was filtered and subjected to a series of centrifugal steps to remove NPCs and non-viable hepatocytes. 


\section{Cryopreservation and thawing of human hepatocytes}

Cells were cryopreserved in CryoStore CS10 solution supplemented with $10 \%$ foetal bovine serum using isopropanol-assisted controlled freezing at $-80^{\circ} \mathrm{C}$ for $3 \mathrm{~h}$ and then stored at $-150^{\circ} \mathrm{C}$ until used. Cryovials were thawed by submerging in a $37^{\circ} \mathrm{C}$ water bath for $2 \mathrm{~min}$. The cell suspension was transferred to $27 \%$ isotonic Percoll in Dulbecco's Modified Eagle's medium (DMEM) and centrifuged to remove dead cells.

\section{Hepatocyte culture}

Papers II-V used hepatocyte cultures that were cultured in short-term 2D monolayers or as 3D spheroids. For spheroid cultures, hepatocytes were resuspended in warm suspension and attachment medium ${ }^{117}$, seeded in ultra-low attachment 384 well plates (Corning), centrifuged, and incubated at $37^{\circ} \mathrm{C}$ with $5 \% \mathrm{CO}_{2}$. The medium was changed 48 hours after seeding and changed every 48-72 hours through the culture period. Liquid handling robots (Hamilton Microlab STAR, Beckman Biomek 2000 or Beckman Biomek NXP) were used for changing media while minimizing disturbance of the spheroid at the bottom of the well.

\section{Characterization of hepatocyte culture evaluations}

Hepatocyte cultures were characterized in detail in paper IV. ATP was measured to evaluate the energy status and viability of the $3 \mathrm{D}$ cultured PHHs. ATP was measured by incubating cultures with AccuMax cell dissociation solution for $30 \mathrm{~min}$ at $37^{\circ} \mathrm{C}$, using the CellTiter-Glo3D assay with slight modifications. The plate was temperature equilibrated at room temperature for $30 \mathrm{~min}$. The CellTiter-Glo3D solution was added and left to incubate on a horizontal plate shaker at room temperature for $20 \mathrm{~min}$, followed by luminescence measurement.

Glucose was measured using Precision XceedPro and Precision PXP glucose sticks following the manufacturer's instructions. All measurements were performed in triplicates.

Albumin secretion was used to measure hepatocyte function. Culture medium was collected and stored at $-80^{\circ} \mathrm{C}$ until analysis. Human albumin was quantified using a human albumin ELISA kit according to the manufacturer's instructions.

Immunohistochemistry (IHC) was used to assess the morphology and localisation of processes such as hypoxia, apoptosis, lipid droplets and proliferation. Immunohistochemistry staining was performed by Tor Halle at the R\&D unit, Department of Clinical Pathology, Uppsala University Hospital. Hepatocytes were treated with pimonidazole for $1 \mathrm{~h}$ for hypoxia staining or 
directly fixed in $4 \%$ formaldehyde in PBS overnight. After fixation, hepatocytes were embedded in paraffin and sectioned in $3 \mu \mathrm{m}$ slices and stained, the slides were scanned, and high-resolution NDPI images were taken.

\section{Liver-specific gene expression panel and ADME proteins}

Investigation of liver-specific proteins and ADME proteins provides information on how consistent the expression of important liver functions is when cells are cultured in vitro. Therefore, we investigated proteins from the liverspecific gene expression panel (LiGEP) ${ }^{118}$ and ADME-related genes. ${ }^{3}$ The expression of these proteins was monitored over the course of the culture's lifetime and cryopreserved PHHs were used as the base line.

\section{Metabolic function}

In Papers III and IV, metabolic function was assessed to measure the metabolic capacity of PHH monolayers and spheroids. Hepatocyte spheroid cultures were incubated with a drug cocktail containing the prototypical cytochrome P450 substrates bufuralol (CYP2D6), diclofenac (CYP2C9), midazolam (CYP3A4), and omeprazole (CUP2C19) in HBSS. Medium was collected and diluted with ice-cold acetonitrile/water (60:40) containing warfarin as an internal standard at $50 \mathrm{nM}$. Primary metabolites for the prototypical substrates were measured using LC-MS/MS. The metabolic function of the hepatocyte monolayers was investigated with diclofenac and midazolam only.

\section{Drug induced liver injury}

In Paper IV, a preliminary study of hepatotoxicity was performed with the hepatotoxic compounds azathioprine, chlorpromazine, diclofenac, and fluconazole, with warfarin as a negative control. PHH spheroids were incubated with the hepatotoxic compounds at $1 \mathrm{x}, 5 \mathrm{x}$ and $20 \mathrm{x}$ times the clinical $\mathrm{C}_{\max }$ of the compounds for 14 days, as described previously. ${ }^{119}$ Viability was assessed by measuring ATP content.

\section{Uptake kinetics}

In Paper V, hepatic uptake transport of 4-(4-(dimethylamino)styryl)-nmethylpyridinium $(\mathrm{ASP}+)$ was measured in 3D cultured PHHs. Prior to uptake experiments, the culture medium was changed to Hank's Balanced Salt Solution (HBSS). Cells were centrifuged, incubated at $37^{\circ} \mathrm{C}$ for 10 minutes, and a solution of HBSS and the model substrate ASP+ was added. Fluorescence was measured using a Tecan Spark microplate reader or visualized using a modified Nikon Eclipse Ti-2 microscope with a Lumencore Spectra-X bandpass filter for excitation. Emission was collected through a HQ610/75 nm filter. 
To analyse $\mathrm{ASP}+$ uptake kinetics, $\mathrm{ASP}+$ concentrations were set to values of 1-50 $\mu \mathrm{M}$. The initial slope was calculated and $K_{m}$ and $V_{\max }$ values were determined with Graphpad Prism 9 using non-linear regression according to the Michaelis-Menten equation (eq 2):

$$
v=\frac{v_{\max } \times[S]}{K_{m}+[S]}
$$

$v$ is the uptake rate, $v_{\max }$ is the maximal uptake rate, $[S]$ is the substrate concentration (ASP+), and $K_{m}$ is the substrate concentration at half $V_{\max }$.

\section{Uptake inhibition}

In Paper V, uptake inhibition studies were performed similarly to the uptake experiments, with the modification that the HBSS contained one of the inhibitors (ketoconazole, verapamil, clomipramine, diltiazem, clotrimazole, or chlorpromazine) at a final concentration of $100 \mu \mathrm{M}$. All inhibitors were investigated for intrinsic fluorescence at the wavelength used for ASP+ measurements. The concentration of ASP+ was $1 \mu \mathrm{M}$.

The inhibition studies were essentially performed as previously described for $2 \mathrm{D}$ cultures. ${ }^{120}$ In brief, spheroids incubated with ASP+ without inhibitors were used to determine the maximal uptake. Inhibition was then calculated as a percentage of the maximal uptake.

\section{Proteomics based deconvolution}

Paper VI investigated whether previously published deconvolution algorithms used for transcriptomic data can also be applied to proteomic data. One partial $(\mathrm{MuSiC})^{121}$ and one complete (Linseed) ${ }^{122}$ deconvolution algorithm were investigated. The partial deconvolution algorithm MuSiC needs cell-type specific data, unlike the complete deconvolution algorithm Linseed, for which the different generated cell groups only need to be annotated. We therefore used a single-cell RNA sequencing database and the UniProt database to annotate output from Linseed. ${ }^{15,113}$

We also investigated whether a simple linear methodology, a constrained linear least squares (LLS) algorithm, could be used. This method was constructed by assuming the following: Let $\mathrm{C}, \mathrm{P}$ and $\mathrm{C}_{\mathrm{t}} \in \mathbb{R}_{+}^{\mathrm{m} \times \mathrm{n}}$ be the non-negative matrix containing protein concentrations in different samples $(C)$, the expression of proteins from the different cell types $(\mathrm{P})$, and the proportions of the different cell types in the samples $\left(\mathrm{C}_{\mathrm{t}}\right)$. Then the matrix $\mathrm{C}$ can be assumed to be the matrix product of $\mathrm{P} \times \mathrm{C}_{\mathrm{t}}$. If we know any two of the three matrices, the problem can be solved using a constrained LLS algorithm. Hence, we alternated between solving for $\mathrm{P}$ or $\mathrm{C}_{\mathrm{t}}$ while keeping the other fixed. This procedure was done using Matlab R2019b with the side constraint that the cell type proportions must sum to one and with a lower bound of zero for $\mathrm{P}$ and 
$\mathrm{C}_{\mathrm{t}}$. No filtering, scaling or identification of marker proteins were performed to keep the method as simple as possible.

The protein concentrations for mixed cell lines, primary liver cells, and liver tissue were calculated using TPA and used as an input for three algorithms. In silico mixing of primary human liver cells was produced by first assigning each cell type a random number from a uniform distribution and divided by the sum of the proportions, which assures that the proportions sum to one. This procedure was repeated to produce proportions for 100 in silico samples. Each cell type proportion was multiplied by a random number assigned from a normal distribution created from measured protein-specific and cell-type-specific means and standard deviations. The generated products were then summed for each individual sample to generate the amount of each protein in each sample, which was then used as input in the algorithms.

Because the partial algorithms need information on cellular composition or cellular expression to work, MuSiC and LLS were not used for the human tissue sample, as it was not possible to collect data on each cell type present in the tissue.

\section{Cultures of human cell lines}

In Paper VI, HEK 293 (human embryonic kidney), Caco-2, (human colorectal carcinoma), and A549 (human non-small cell lung cancer) cell lines were used. Cells were grown in $\mathrm{T} 75$ flasks at $37^{\circ} \mathrm{C}$ in $5 \% \mathrm{CO}_{2}$ for HEK293 and A549 and $10 \% \mathrm{CO}_{2}$ for Caco-2 until 80-100\% confluency. HEK293 and A549 cells were cultured in Dulbecco's Modified Eagle's medium (DMEM) supplemented with $10 \%$ fetal bovine serum (FBS), $1 \%$ penicillin-streptomycin (PEST) and 2mM L-glutamine. Caco-2 cells were cultured in DMEM supplemented with $10 \%$ FBS and $1 \%$ nonessential amino acids. Cell lines were used singly or in mixtures of known proportions that were blinded to the operator. All samples contained a total of six million cells each. 


\section{Results and discussion}

\section{Inter-individual variability of ADME proteins in the human liver}

One of the aims of this thesis was to investigate inter-individual variability of ADME proteins in the human liver by comparing the protein expression with gene expression. Previous work by our collaborators that used semi-quantitative western blotting for protein expression was not conclusive regarding the extent of variability, so we used MS-based proteomics, which provides data of higher quality than western blotting. ${ }^{123}$ We developed a method for absolute quantification of protein expression using targeted proteomics, and performed this procedure on 149 membrane-enriched human liver samples (Figure 5). Of these 149 samples, 15 were available as a whole-cell lysate, and a good correlation between whole cell lysates and membrane enrichment was observed. An enrichment factor of 3.15 was determined for the membrane-enriched fractions (Figure 5), which is similar to previous reports. ${ }^{93}$

A correlation between transporter protein abundances and mRNA levels measured using qPCR was observed. Genotyping was also performed, but could not solely explain the observed inter-individual variability. A detailed investigation was therefore performed on a single transporter, NTCP, to identify additional factors that could explain the inter-individual variation. 

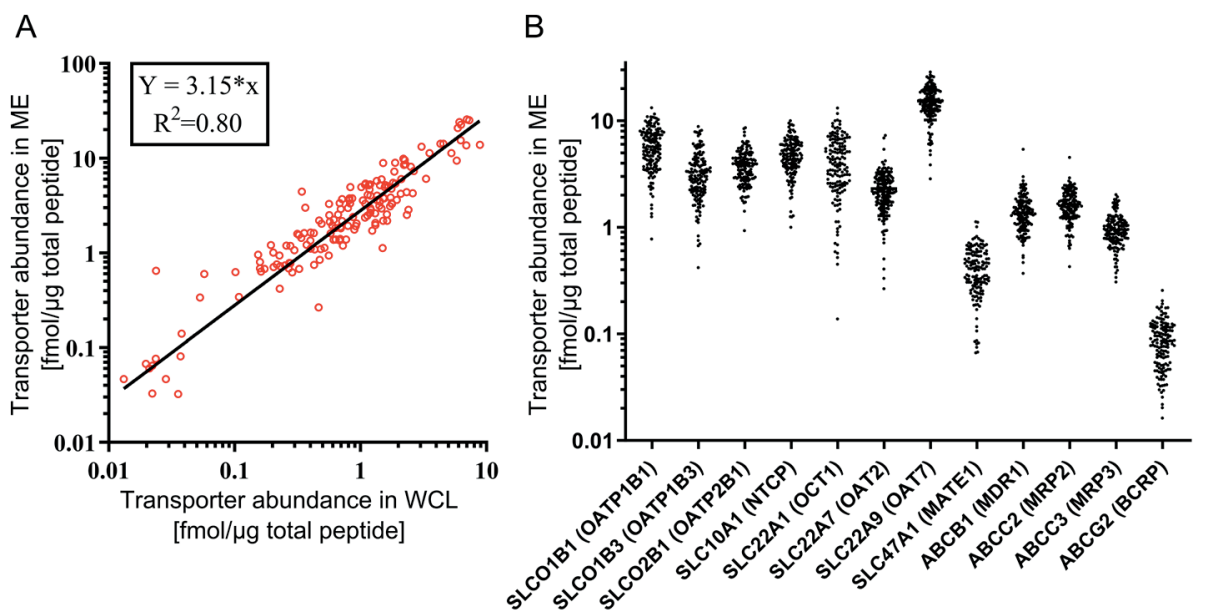

Figure 5. Transporter abundance in 149 human liver samples measured by targeted proteomics. A, Correlation between transporter expression in 15 liver samples measured in membrane-enriched fractions and in whole-cell lysates. The equation for the trend line and the goodness of fit are shown in the top left corner. B, Transporter abundance in 149 human liver samples quantified by a mass spectrometry-based targeted approach.

\section{Inter-individual variability of the hepatic bile acid and drug transporter NTCP (Paper I)}

Paper I aimed to investigate the cause of the observed variation among individuals in protein expression of the bile acid and drug transporting protein NTCP. The mRNA expression levels of NTCP were measured using real-time PCR and the protein expression was quantified by LC-MS/MS-based targeted proteomics. The correlation between protein expression and mRNA expression (Figure 6A) was significant (but weak). The protein expression varied about ten-fold, while the mRNA expression varied about 40 -fold.

Both protein and mRNA expression were significantly affected by the nongenetic factors smoking, alcohol consumption, and inflammation (C-reactive protein $[\mathrm{CRP}]$ ), and mRNA expression was also affected by the factors age and cholestasis (Figure 6B). 


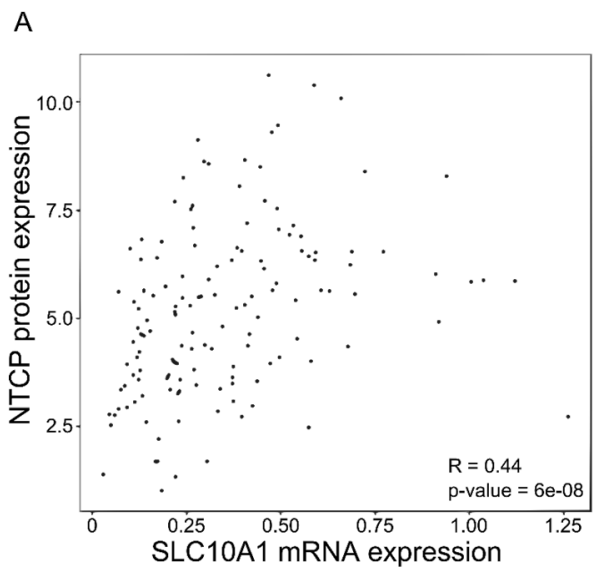

\begin{tabular}{lll} 
B & & \\
\hline Non-genetic factors & mRNA & Protein \\
\hline $\begin{array}{l}\text { Sex } \\
(68 \text { male vs. } 75 \text { female) }\end{array}$ & n.s. & n.s. \\
$\begin{array}{l}\text { Age } \\
\text { [median = 56; range 7-85 years] }{ }^{*}\end{array}$ & $\begin{array}{l}0.03 \\
r_{\mathrm{s}}=-0.19\end{array}$ & n.s. \\
$\begin{array}{l}\text { Cholestasis } \\
\text { (23 yes vs. } 117 \text { no) }\end{array}$ & 0.03 & n.s. \\
$\begin{array}{l}\text { Medication } \\
\text { (38 yes vs. } 105 \text { no) }\end{array}$ & n.s. & n.s. \\
$\begin{array}{l}\text { Smoking } \\
\text { (29 yes vs. 110 no) }\end{array}$ & 0.006 & 0.017 \\
$\begin{array}{l}\text { Alcohol consumption } \\
\text { (46 yes vs. } 92 \text { no) }\end{array}$ & 0.002 & 0.005 \\
$\begin{array}{l}\text { CRP } \\
\text { [range 0.1-21.1mg/ml] }\end{array}$ & $<0.0001$ & 0.0009 \\
\hline *Spearman correlation & $r_{\mathrm{s}}=-0.33$ & $r_{\mathrm{s}}=-0.28$ \\
\hline
\end{tabular}

Figure 6. Correlation between mRNA expression, protein expression, and non-genetic factors. A, Correlation between mRNA expression and protein expression in human liver samples. mRNA expression was measured using qPCR and protein abundance quantified using LC-MS/MS. Spearman's rank correlation (R) and unadjusted p-values are given. B, Association between non-genetic factors, mRNA, and protein expression. The effects of non-genetic factors were tested with the Wilcoxon-Mann-Whitney test or using Spearman correlation.

Genomic factors were also investigated. Genetic variants of the NTCP gene (SLC10A1) were analysed and 12 rare variants were found. Because these variants were only found heterozygously and in two individuals, their influence was not statistically tested. Twenty-two more common variants (minor allele frequency higher than $1 \%$ ) were found, however, these variants did not affect mRNA and protein expression significantly.

To further extend the search for genomic factors associated with mRNA and protein expression of NTCP, a genome-wide association study (GWAS) was performed using imputed Single Nucleotide Polymorphism data. Only one imputed variant on chromosome 8 was significantly associated with mRNA expression (Figure 7). This variant was not significantly associated with protein expression, and no other association was found with confidence over a genome-wide significance level. 


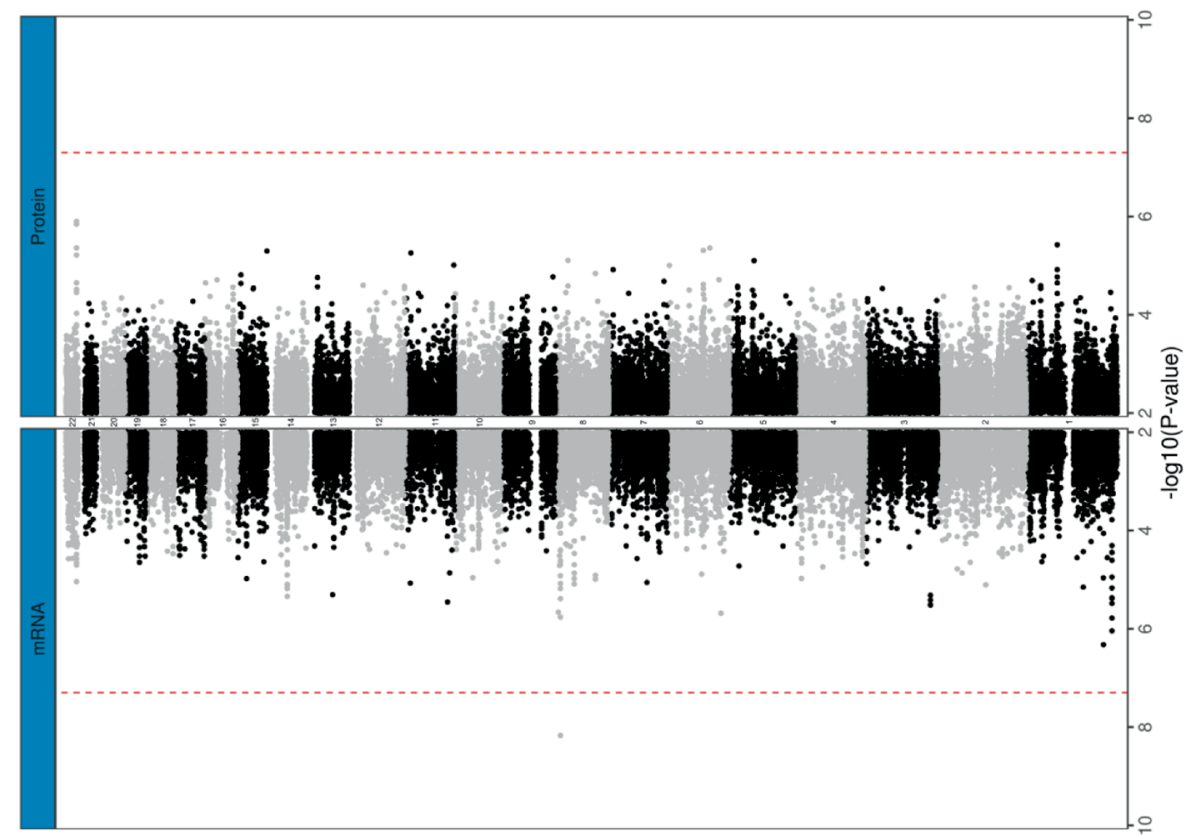

Figure 7. Genome-wide association study (GWAS) of mRNA expression and protein abundance of NTCP in human liver tissue. The top of the Manhattan plot shows the association with protein abundance and the bottom shows the association with mRNA expression. The red lines indicate the genome-wide significance level.

Because no genetic variant was found that was significantly associated with mRNA and protein expression of NTCP, epigenetic factors were investigated. Two significant associations between DNA methylation at individual $\mathrm{CpG}$ sites and protein expression were observed. Furthermore, cellular experiments with methylated SLC10A1 promoter fragments showed lower expression than mock-methylated samples. Treatment with AZA (a well known methylation inhibitor) led to an increase in SLC10A1 mRNA expression.

Lastly, the correlation between endogenous metabolites and mRNA/protein expression of NTCP was investigated. Betaine and N-Alpha-Acetyl-Llysine showed significant association with both mRNA and protein expression. Betaine is an osmolyte that plays an important role as a methyl donor, and acetyl-lysines play crucial roles in epigenetic regulation. ${ }^{124,125}$

In summary, the genetic variants found could not explain the inter-individual variability of NTCP. Patient factors like smoking and epigenetic factors significantly correlated with NTCP expression. This study highlights the need for comprehensive and various omics-based approaches to understand interindividual variability of protein expression in humans. 


\section{Hepatocyte isolation, characterisation, and restoration (Papers II-III)}

Papers II and III focused on characterising the variability observed in isolated and cryopreserved human hepatocytes. An initial characterisation based on cell shape, cell stretching, cell boundaries, debris/dead cells, and confluency was done on monolayer cultured hepatocytes from 54 donors. This characterisation developed into a monolayer score which was used to classify batches of hepatocytes into high-, mid-, and low-quality groups.

While comparing batches to each other, it was observed that the size of the hepatocytes varied between batches. An investigation of the proteomic and functional differences between different sizes of hepatocytes showed similar characteristics to those observed for hepatocytes in the different zones of liver lobules.

The quality of hepatocyte batches varied, and such variability is a wellknown problem. ${ }^{60,61}$ It was observed that batches of lower quality had many hepatocytes that were not able to attach to the ECM-coated plates. Also, lowperforming batches had difficulties in forming spheroids (Figure 8A). Attached and non-attached hepatocytes were collected and subjected to proteomics analysis to explore the reasons for the attachment difficulties. Hepatocytes that did not attach showed considerable cell stress and apoptosis activation. A screening for ways to post-thaw rescue such batches was performed and Z-VAD-FMK, a pan-caspase inhibitor, resulted in a dose-dependent increase in attachment efficiency. Furthermore, Z-VAD-FMK facilitated the formation of $3 \mathrm{D}$ cultures in low-performing hepatocyte batches and increased the attachment efficiency without influencing the results of metabolic function or albumin secretion in 3D cultured PHHs (Figure 8B-C).

In sum, size-dependent variability in hepatocyte batches seems to reflect zonal function and a simple protocol was developed that markedly increased attachment and spheroid formation ability in suboptimal batches of hepatocytes. 


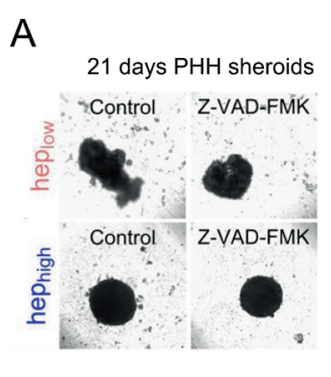

Monolayer score: hep $_{\text {low }}$

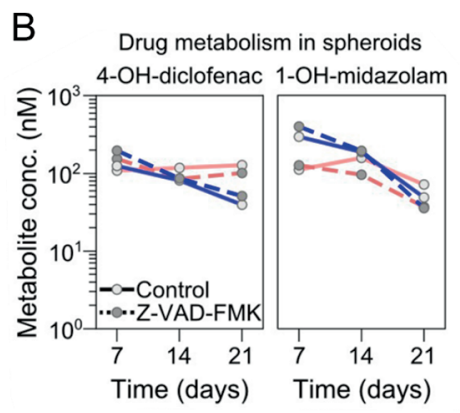

hep $_{\text {high }}$
C

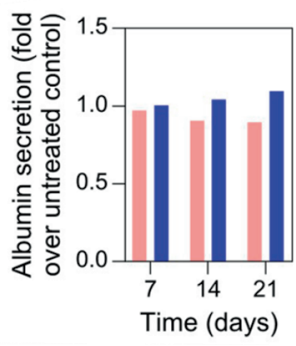

Figure 8. Hepatocyte function after treatment with Z-VAD-FMK. Two batches of cryopreserved $\mathrm{PHH}$ representing low- and high-performing batches, according to the monolayer score, were used. A, Spheroid formation after 21 days of culture with and without Z-VAD-FMK addition during the initial seeding. B, Metabolite formation of spheroid cultures treated with and without Z-VAD-FMK. C, Albumin secretion of cultures treated with and without Z-VAD-FMK.

\section{Maintenance of hepatocyte differentiation and function in 3D spheroid cultures (Paper IV)}

Even when using high-performing batches of hepatocytes, extensive functional variability can be observed across laboratories, such as the variability in measured metabolite formation rates. ${ }^{22,126,127}$ A possible reason for this inter-lab variation could be that different culture conditions are used. We therefore investigated two commercial media with undisclosed contents, Hepatocyte Maintenance Medium (HMM) and Cellartis Power Primary HEP Medium (PPM), and two conventional media, William's E (WE $\mathrm{HG}_{\mathrm{H}}$ ) and DMEM/F12 (DF $\left.{ }_{\mathrm{HG}}\right)$ with defined contents. Variants of the William's E (WE) and DMEM/F12 (DF) media with glucose and insulin levels at in vivo fasting levels $\left(\mathrm{WE}_{\mathrm{NG}}\right.$ and $\mathrm{DF}_{\mathrm{NG}}$ ) were also investigated. $\mathrm{WE}_{\mathrm{NG}}$ and $\mathrm{DF}_{\mathrm{NG}}$ were also supplemented with physiological levels of zinc $\left(\mathrm{WE}_{\mathrm{NG}^{+}}\right.$and $\left.\mathrm{DF}_{\mathrm{NG}^{+}}\right)$. In total, eight different media were investigated.

Depending on culture media, a several-fold variation in albumin secretion and ATP content could be observed (Figure 9). Interestingly, the reduced amount of glucose and insulin in $\mathrm{WE}_{\mathrm{NG}}$ and $\mathrm{DF}_{\mathrm{NG}}$ did not substantially affect the ATP content and albumin secretion, indicating that high glucose and insulin levels are not needed to maintain viable hepatocyte cultures. 
A

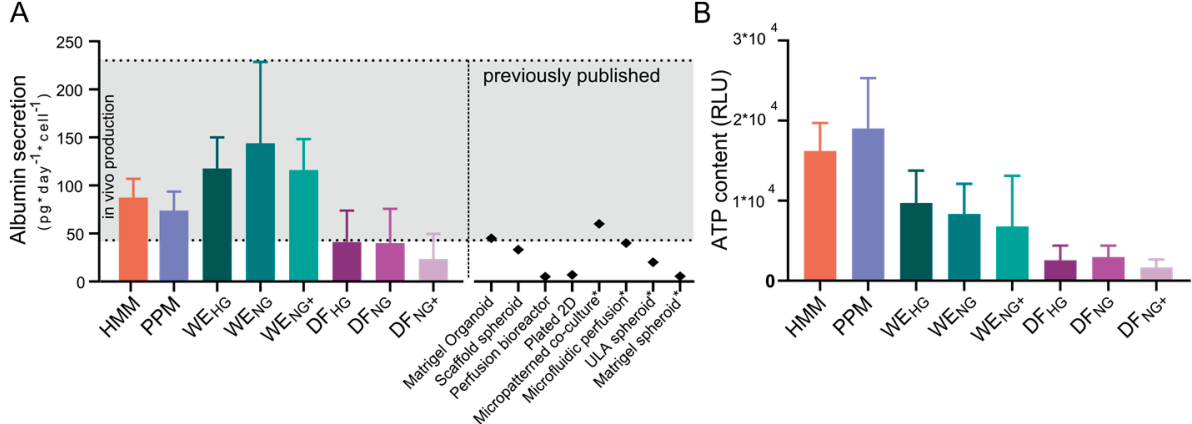

Figure 9. Albumin secretion and ATP content of PHH spheroids cultured in eight different culture media over three weeks in culture. A, Albumin secretion was measured in the cultured medium using an ELISA kit. The grey area represents in vivo production ranging from dormant to maximal production. On the right, previously published levels of in vivo albumin secretion in various culture formats are shown as a reference. B, ATP content over three weeks in culture.

Immunohistochemistry was used to further assess the detailed morphological changes in PHH spheroids cultured in differing media (Figure 10). Spheroids cultured in DFs media exhibited an asymmetric and fragile 3D structure compared to spheroids in the other media. A possible reason for this observation could be that DFs media lacks ascorbic acid, which is important for cytoskeleton and cell junction function. ${ }^{128-130}$

Spheroids cultured in low glucose and low insulin media manifested less staining for the lipid droplet marker PLIN2. Conversely, spheroids cultured in high glucose and high insulin media showed more staining, which possibly reflects a more steatotic phenotype. High glucose, high insulin, and free fatty acid have previously been used to create models for steatosis and insulin resistance. $^{70}$

Hypoxia is important to consider for any culture containing cells with limited access to dissolved oxygen in their culture medium. Use of PPM led to strong staining for the hypoxic marker pimonidazole. A few of the other media showed some hypoxic cells evenly distributed in the spheroids, but no hypoxic core could be observed. Because the composition of PPM is not disclosed, it is difficult to provide an explanation for the staining. However, commonly used medium components like cobalt have been implicated in hypoxia. ${ }^{131}$ 

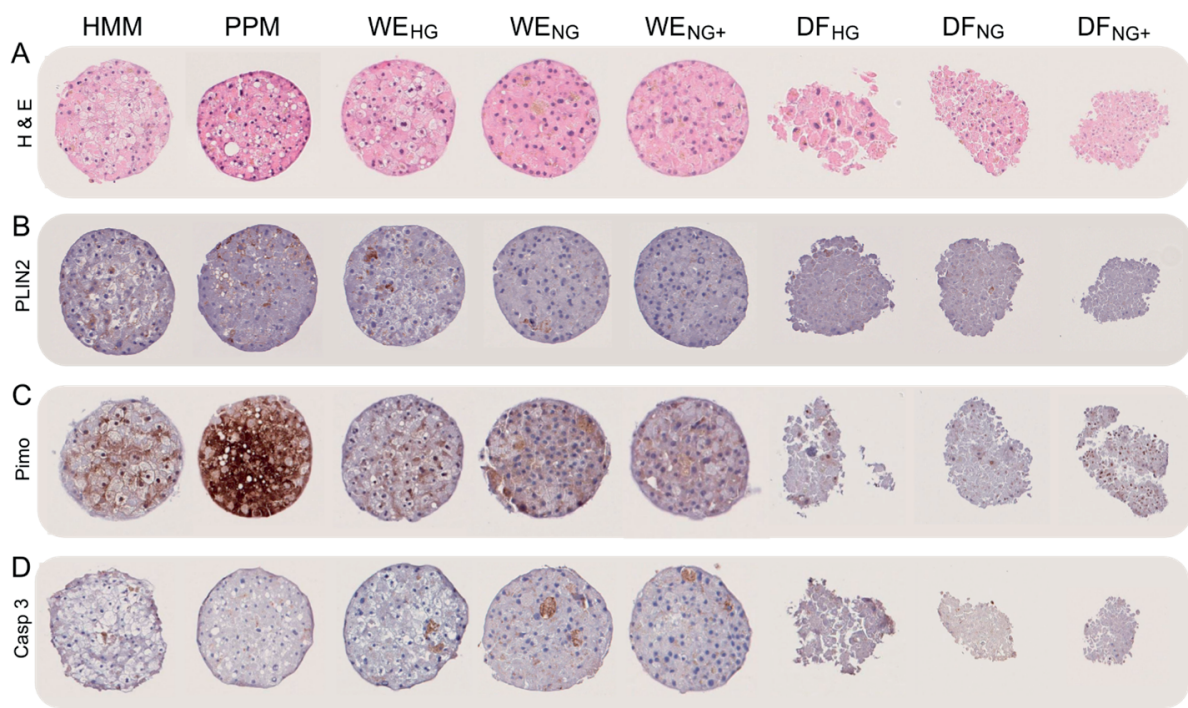

Figure 10. Immunohistochemistry of PHH spheroid culture in eight different media for three weeks. A, Haematoxylin and eosin staining. B, Lipid deposit staining using adipolin. C, Hypoxia staining using pimonidazole. D, Apoptosis staining using caspase 3 .

The global proteomes of PHH spheroid cultures in different media were also investigated and compared to freshly thawed human hepatocytes (Figure 11). The proteomic profiles of spheroids cultured in PPM deviated from those of freshly thawed hepatocytes and spheroids cultured in the other media. PPM cultures also had the most strongly deviating expression of proteins belonging to the LiGEP panel. Interestingly, spheroids cultured in different media clustered together by time point (Figure 11A) with the exception of those grown in PPM. This suggests that an underlying culture-time-dependent change has a large impact on the proteomes of PHH spheroids independent of the culture media used. 
A

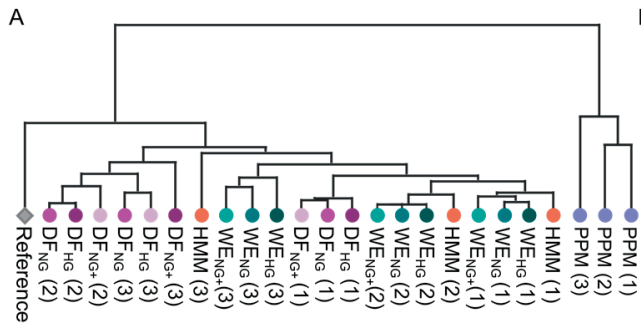

B

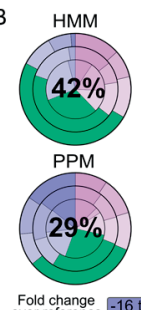

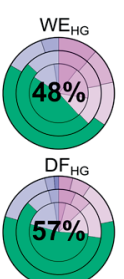
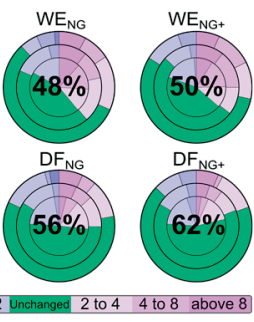

Figure 11. Proteome of PHH spheroids cultured in eight different media. A, Hierarchical clustering of the proteomes where branch length is scaled using Euclidean distance. PHH spheroid proteomes were analysed after one, two, and three weeks of culture (parentheses). B, Protein expression of genes from the LiGEP panel compared to cryopreserved PHHs. The average percentage of proteins that changed less than 2-fold are shown in the middle of each pie chart. The pies show data for weeks one (inner circle) through three (outside ring).

To investigate the time dependent variation observed in the hierarchical clustering, a pathway analysis was performed. The pathway analysis showed that independent of culture medium, extracellular space and extracellular matrix proteins increased in spheroids cultured for one week. A plausible explanation is that PHHs need to re-establish cell-cell and cell-matrix contacts when forming the spheroids. The upregulation of serum proteins could possibly be due to the absence of those proteins in the culture media (with the exception of bovine serum albumin in PMM). Similar observations have been previously reported for PHH spheroid cultures using transcriptomics. ${ }^{132}$

During the second week of culture, spheroids changed less than they did during the first week, and in most media, expression of ribosomal proteins decreased. In the DFs media, additionally, expression of cytoskeletal proteins decreased, in line with the brittle spheroids observed via IHC (Figure 12).

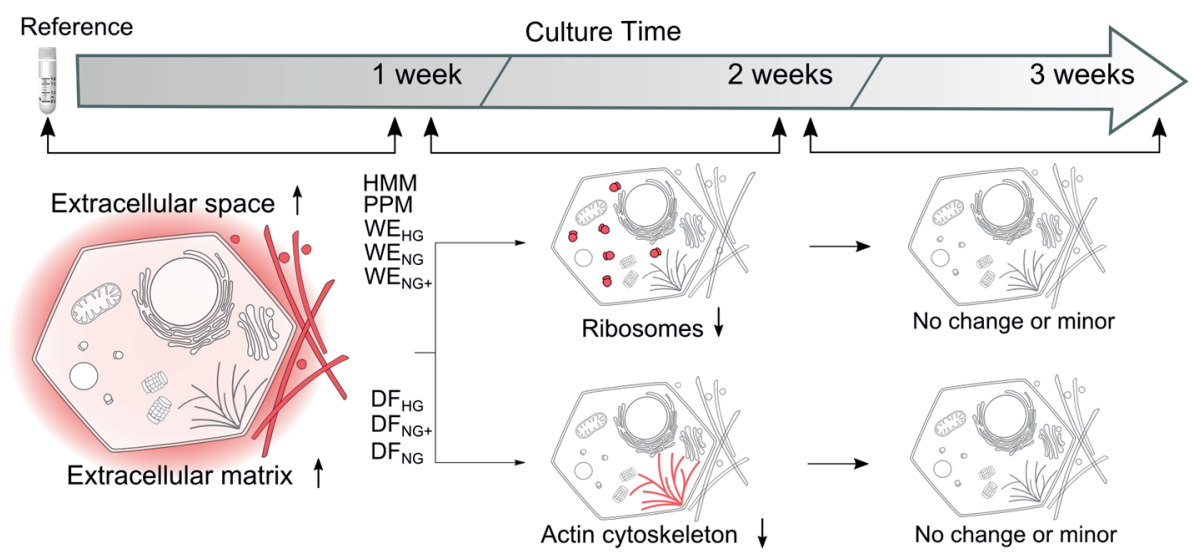

Figure 12. Pathway analysis of PHH spheroids cultured in eight different media. Selection of significantly (false discovery rate of 0.05) up- and down-regulated cellular components (red) from pathway analysis. 
Because PHH cultures are regularly used for drug metabolism and toxicity studies, the expression of ADME-relevant proteins was investigated (Figure 13). Out of 682 ADME-related genes, ${ }^{3} 315$ were found in the PHH spheroid cultures, similar to the number found previously in $\mathrm{PHH}^{133,134}$ Over time, ADME protein expression became more comparable to that observed in freshly-thawed hepatocytes, much like the changes in LiGEP protein levels (Figure 11B). Differences in glucose and insulin in the two William's E and DMEM/F12 medium variants did not influence ADME protein expression. Again, the profile of PPM-cultured cells deviated both from other media treatments and freshly thawed hepatocytes.
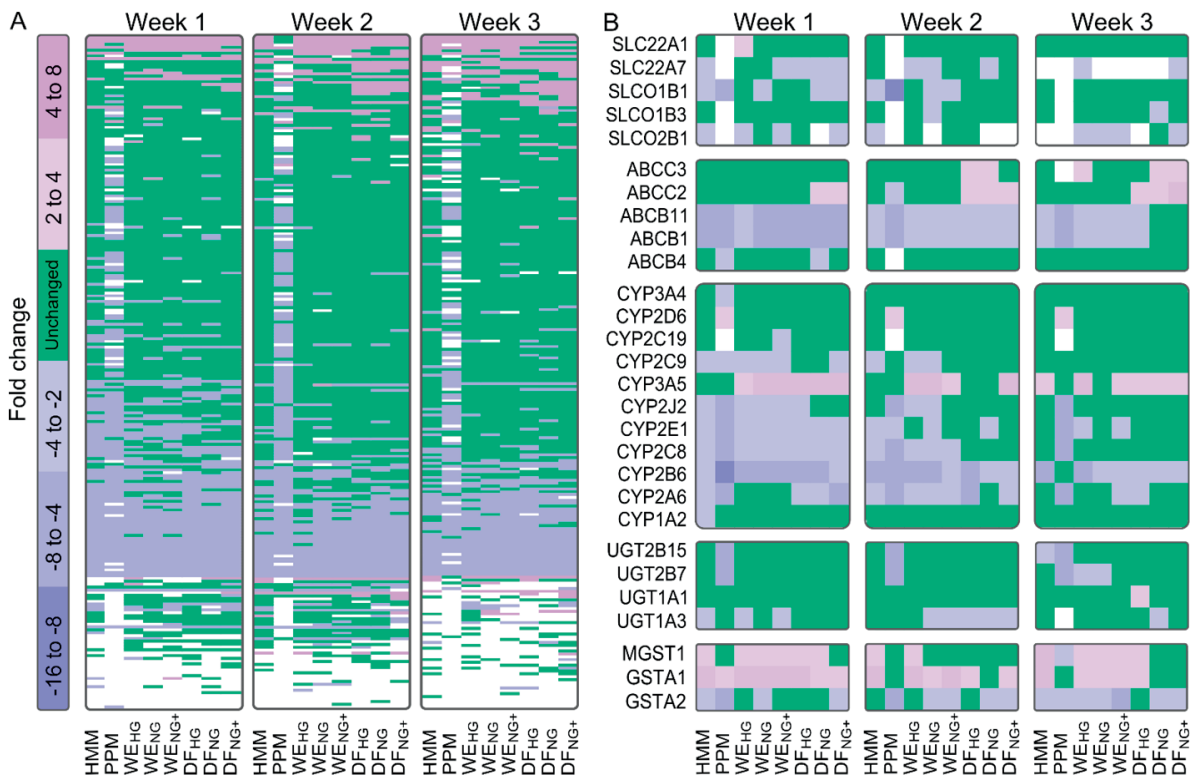

Figure 13. Heat map of ADME-related protein expression. A, Protein expression of 315 ADME-related genes ${ }^{3}$ compared to expression in freshly thawed PHHs. B, Protein expression of clinically relevant drug transporters and metabolising enzymes compared to expression in freshly thawed $\mathrm{PHH}$.

Even though the expression of many ADME-related proteins remained comparable to that of freshly thawed hepatocytes for several weeks, the correlation between protein expression and function has been known to vary. ${ }^{135,136}$ Therefore, metabolite formation from four prototypical substrates for the most important CYP enzymes ${ }^{40}$ was investigated using LC-MS/MS (Figure 14). In contrast to protein expression, the metabolite formation rate decreased over time, indicating that the optimal window for routine metabolism studies in spheroids is directly after spheroid formation during the second week of culture. Overall, a higher similarity to freshly thawed PHHs was observed for spheroids cultured in HMM or William's E media. 


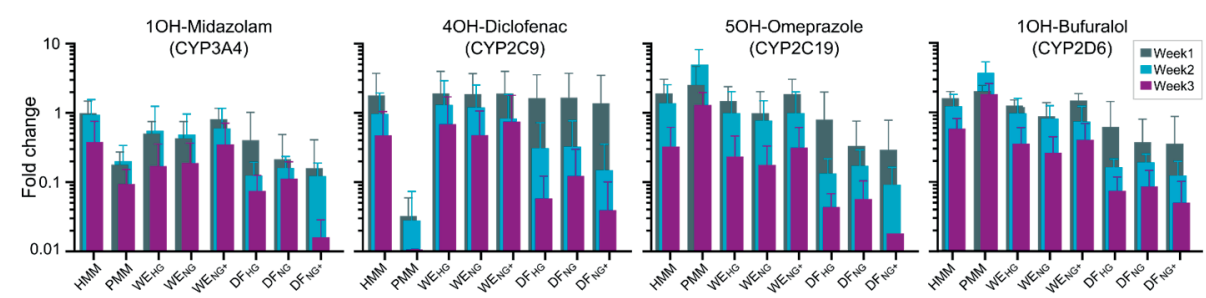

Figure 14. Metabolite formation of PHH spheroids cultured in eight different media after one, two, and three weeks. Prototypical model substrates were chosen for the four most important CYP enzymes. ${ }^{40}$ Metabolites were measured using LC-MS/MS and metabolite formation was compared to freshly thawed PHHs in suspension.

In summary, differences in function and morphology could be observed in spheroids cultured in different culture media. In general, spheroids cultured in HMM and William's E media displayed the most similar phenotype to isolated $\mathrm{PHH}$. In vivo fasting levels of glucose and insulin maintained a normal $\mathrm{PHH}$ phenotype with no signs of steatosis transformation and performed as well as media with high levels of glucose and insulin. These findings will hopefully contribute to more rigorous and standardised protocols for PHH spheroid cultures with less variability and better reproducibility.

\section{Transporter kinetics in 3D cultured human hepatocytes (Paper V)}

Because PHH spheroids maintain a differentiated phenotype suitable for studying metabolic function for weeks, an investigation to further expand the applicability of PHH spheroids for uptake kinetic studies was performed. Kinetics of the organic cation transporter 1 (OCT1) were investigated using the fluorescent cation compound $\mathrm{ASP}+$.

It was previously shown that $\mathrm{ASP}+$ is also a substrate for the organic cation transporters (OCTs), novel organic cation transporters (OCTNs), and multidrug and toxin extrusion family members (MATEs). ${ }^{137-139}$ Protein expression for these transporters was investigated using global proteomics (Figure 15A). OCT1 was the most highly expressed transporter of ASP+, followed by OCT3 with about 7-fold lower expression.

$\mathrm{ASP}+$ is non-fluorescent in medium, but becomes fluorescent upon entering a cell. Being the first cellular point of contact, only the outer hepatocytes, i.e. those forming the surface area of the spheroid, render ASP+ fluorescent (Figure 15B). Internal hepatocytes merely transport already fluorescent ASP+ further into the spheroid (Figure 15C) and can thus be viewed as "inactive". Therefore, $\mathrm{K}_{\mathrm{m}}$ should be similar to values obtained in $2 \mathrm{D}$ culture systems, although $\mathrm{V}_{\max }$ will be dependent on the amount of OCT1 on the surface of the spheroid. 

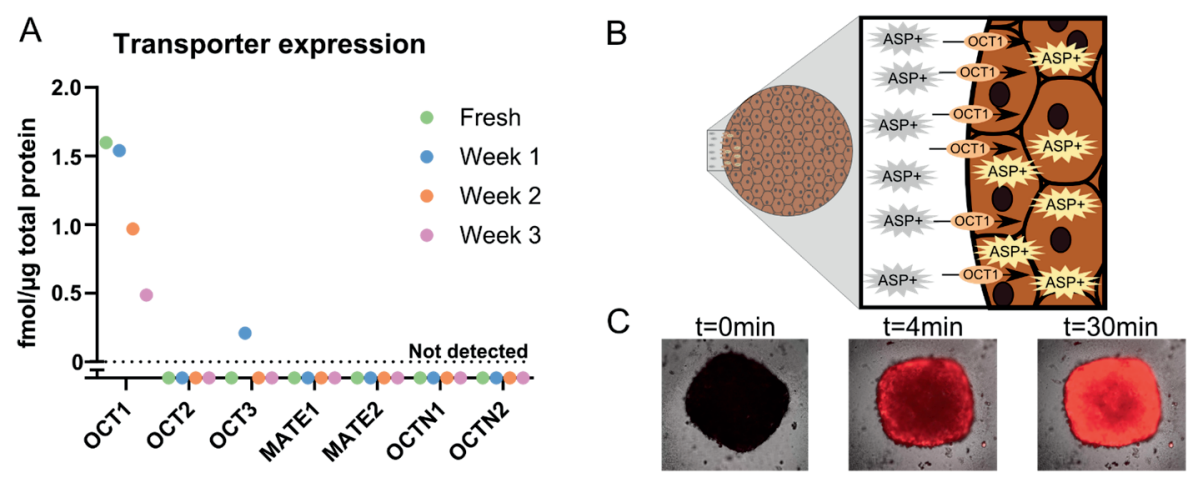

Figure 15. Protein expression of ASP+ transporters and uptake mechanism in $\mathrm{PHH}$ spheroids. A, Protein expression of ASP+ transporters measured and quantified using nano-LC-MS/MS and TPA. B, Uptake mechanism of ASP+ in PHH spheroids. OCT1 expression at the spheroid surface is the determining factor for ASP+ uptake and hence fluorescence. C, Fluorescence of $5 \mu \mathrm{M}$ ASP + in PHH spheroids cultured for one week.

Time- and concentration-dependent uptake of ASP+ was measured and kinetic parameters were acquired using non-linear regression for Michaelis-Menten kinetics (Equation 2, page 31). An apparent affinity of ASP+ for OCT1 $\left(\mathrm{K}_{\mathrm{m}}\right)$ of $17.4( \pm 1.17) \mu \mathrm{M}$ and maximal turnover rate $\left(\mathrm{V}_{\max }\right)$ of $347( \pm 9.5) \mathrm{RFU} / \mathrm{min}$ were calculated. The $K_{m}$ value was similar to those previously found in $2 \mathrm{D}$ monolayers and suspensions. ${ }^{120,137,140-142}$

A decrease in OCT1 expression was observed in PHH spheroids over time. The uptake rate of $1 \mu \mathrm{M}$ ASP+ was measured in PHH spheroids cultured for one and two weeks (Figure 16A). The fold change in uptake rate between the two weeks was comparable to the fold change observed for the protein expression (Figure 16B), which indicates that OCT1 expression decreases uniformly on the inside and at the surface of the spheroids. If reduced OCT1 expression was predominantly taking place on the surface of the spheroid, a greater reduction in the uptake rate would be observed. Conversely, if OCT1 expression was predominantly reduced in the interior of the spheroid, a smaller reduction in uptake rate would have been observed. 

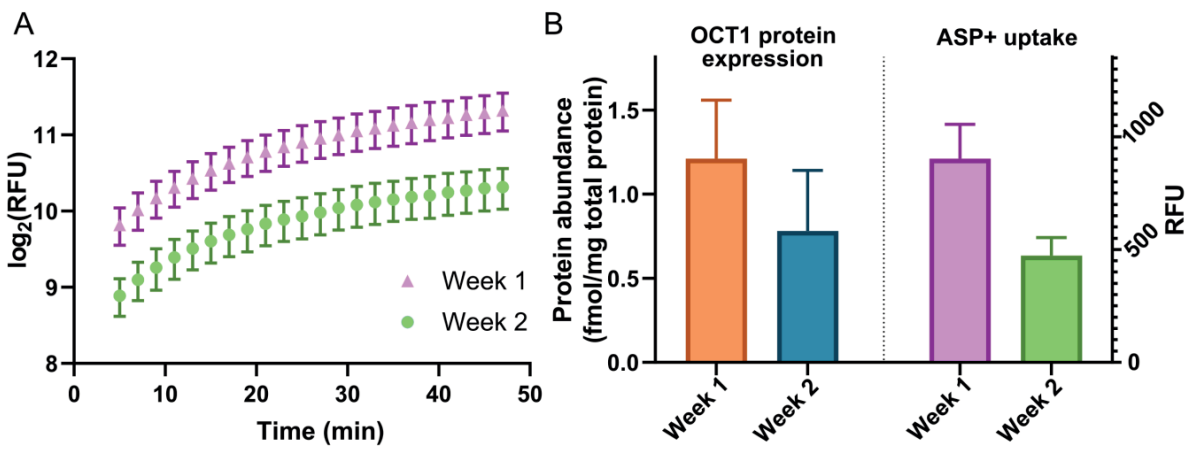

Figure 16. Correlation of ASP+ uptake and OCT1 expression in PHH spheroids cultured for one and two weeks. A, Uptake of $1 \mu \mathrm{M}$ ASP+ of one- and two-week-old PHH spheroids ( $\mathrm{n}=10-12)$. B, Protein expression and fluorescence of ASP+ uptake for one- and two-week-old PHH spheroids. Points indicate means and error bars show standard deviations.

To investigate whether drug-drug interaction (DDI) studies could be performed in PPH spheroids, the effects of six drugs known to inhibit OCT1 were investigated, using $\mathrm{ASP}+$ as a victim drug. These six drugs inhibited up to $60 \%$ of the maximal uptake of ASP+ (Figure 17A). The decrease of ASP+ uptake was also visualised with a mostly non-fluorescent surface in the presence of inhibitors (Figure 17B), which clearly indicates that inhibition of OCT1 mediated uptake is possible in PHH spheroids, implying that DDI studies are possible in a model more in vivo-like than conventional PHH 2D monolayers are.

In summary, we investigated and tested the applicability of PHH spheroids for transport studies using a fluorescent OCT1 substrate, ASP+. Kinetic parameters were quantified and uptake of ASP+ was visualized. Six drugs known to inhibit OCT1 decreased the uptake of ASP+, suggesting that our assay can also be used to study drug-drug interactions.

A

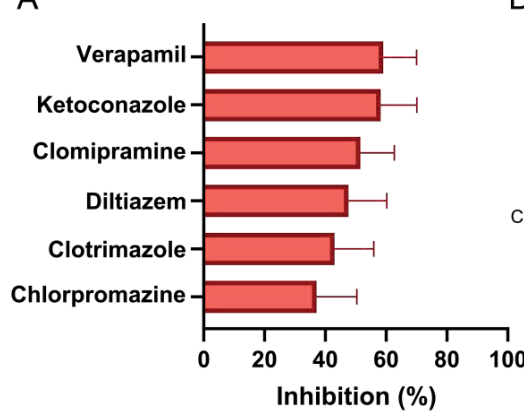

B

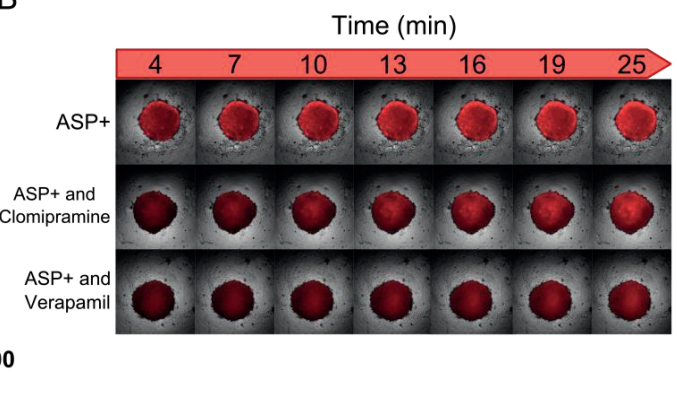


Figure 17. Inhibitory effects of six drugs on OCT1 mediated ASP+ uptake in PHH spheroids. A, PHH spheroids were treated with $100 \mu \mathrm{M}$ of six drugs with known OCT1 inhibitory effects and ASP+ uptake was measured. Values are given as percentage of untreated uptake. B, Uptake of ASP+ alone and together with inhibitory drugs was monitored for 25 minutes.

\section{Proteomics-informed deconvolution in human liver tissue (Paper VI)}

To investigate whether observed inter-individual variability in human liver tissue could be caused by varying cell type compositions, we attempted to deconvolute global proteomics data obtained from a collection of human liver proteomes. First, we investigated the possibility of deconvoluting simple mixtures containing three different cell lines (HEK 293, Caco-2, and A549) in different predefined mixtures. Second, we examined the possibility of deconvolution in in silico mixtures of primary human liver cells (endothelial cells, hepatocytes, Kupffer cells and stellate cells). Third, deconvolution on global proteomics data from human liver tissues was performed.

Nearly 7500 proteins were identified via global proteomics analysis of the three selected cell lines (Figure 18). More than $90 \%$ of these proteins were found in all three cell lines and only around 80 proteins, or $3 \%$ of the total proteome, were unique for each cell line, which is conform with previous findings suggesting that less than $5 \%$ of all proteins are tissue-specific. ${ }^{114}$ The concentrations of the ranked proteins showed a very similar distribution in the cell lines.
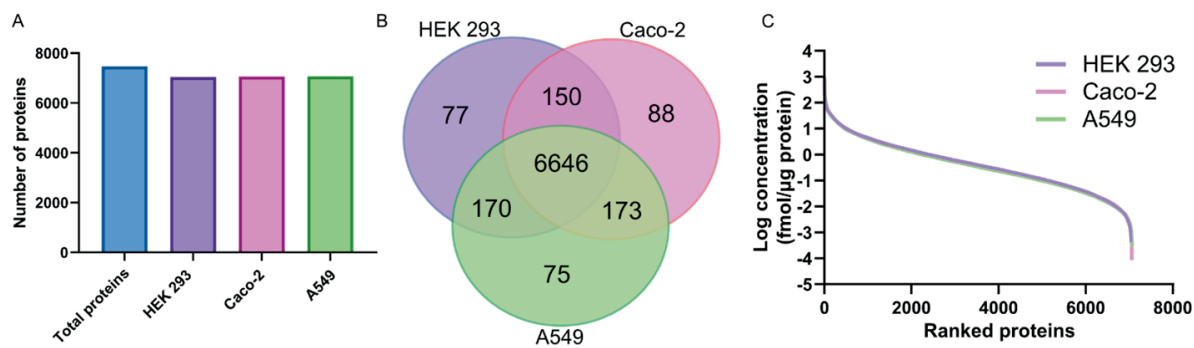

Figure 18. Global proteomics on three different cell lines used for deconvolution. A, Number of proteins detected and quantified using nano-LC-MS/MS for each cell line. B, Shared proteins in the different cell lines. C, Ranked protein abundance for each of the three cell lines.

Three different algorithms (LLS, MuSiC, and Linseed) were used to attempt to deconvolute different mixtures of the three cell lines. MuSiC and Linseed calculated the proportions in the different mixtures accurately, while the LLS method did not properly discern the different cell proportions in several samples (Figure 19). Various biases have previously been observed when using 
transcriptome data and been associated with cell type-specific RNA content, ${ }^{122}$ but here, for MuSiC and Linseed, no systematic over- or underprediction of a specific cell type could be observed. The absence of such bias could be explained by the similar size of the cell lines, ${ }^{143-145}$ because size correlates with protein content. ${ }^{146,147}$ Furthermore, the protein abundance is measured as the amount of a given protein divided by the total amount of all protein, possibly correcting for protein content variations.

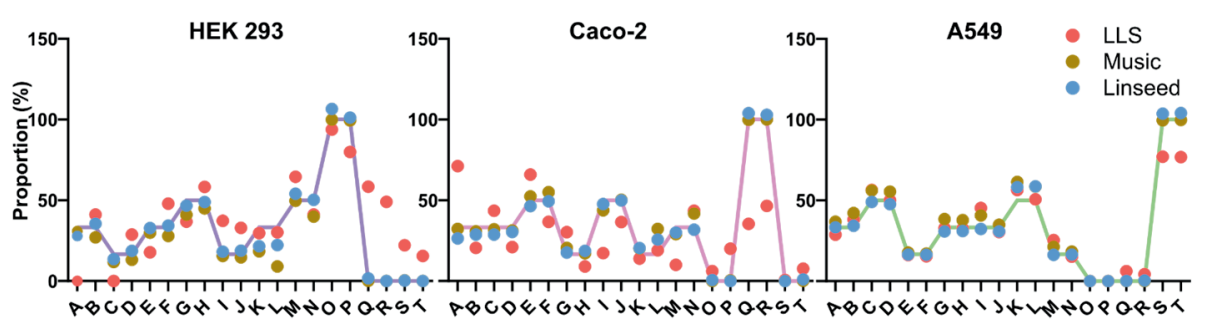

Figure 19. Proteomics-based deconvolution of mixed samples for the three cell lines. The proportions of the different cell lines in samples A-T ( 20 samples) are shown by the line. Dots indicate the predicted proportion of the cell lines for the three algorithms.

Next, proteomics data from four isolated primary human liver cells were used to produce a total of 100 in silico samples with varying proportions of the different cell types. All three algorithms produced estimates of the cell type proportions resembling the theoretical ones, and Lin's concordance correlation coefficient was close to one (Figure 20). MuSiC and Linseed outperformed the LLS algorithm in this case as well.

LLS

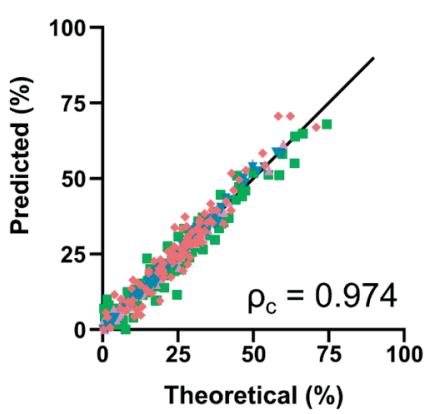

MuSiC

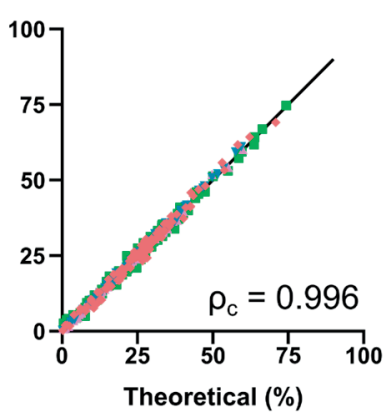

Linseed

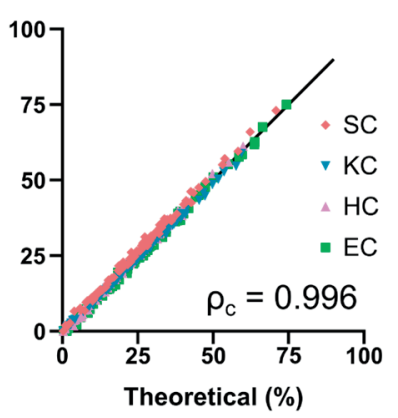

Figure 20. Proteomics-based deconvolution of in silico mixtures of the four major liver cell types isolated from human liver. The figure shows the predicted versus actual cell type proportions in 100 samples for the three deconvolution algorithms. The four isolated cell types are hepatic stellate cells (SCs), Kupffer cells (KCs), Hepatocytes (HCs), and endothelial cells (ECs). Lin's concordance correlation coefficient is given in the figures. 
Because both our in vitro and in silico deconvolution results for cell lines and primary human liver cells were encouraging, global proteomics data from 56 human liver tissue samples from the COCKTAIL study ${ }^{136,148}$ were deconvoluted. Since LLS did not perform well and MuSiC is a partial deconvolution algorithm that requires data on the purified cell types in the samples, Linseed was chosen for the tissue studies.

Linseed produced eight different annotated groups, four of which were hepatocytes, endothelial cells, stellate cells and erythroid cells. One group (group 5) comprised of a mixture of Kupffer cells, T cells, and NK cells. The last three groups contained extracellular proteins from the lumen, space of Disse, and bile canaliculi/ducts, respectively.

To assess the produced proportions, average values were compared to previously published data. ${ }^{7}$ The proportions were similar to those of the volume of each corresponding group (Figure 21).

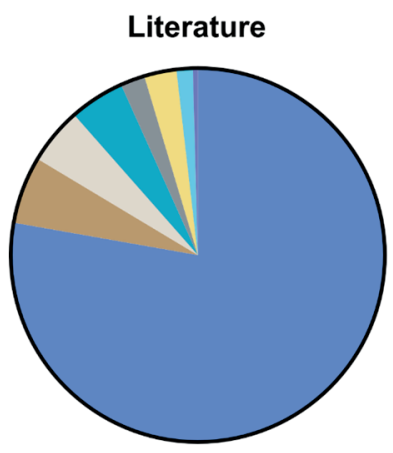

\begin{tabular}{|c|c|c|}
\hline \multicolumn{3}{|c|}{ Liver volume of groups } \\
\hline Volume (\%) & Group & Part (\%) \\
\hline 77.80 & Hepat & 73.68 \\
\hline 5.83 & Lumen & 5.90 \\
\hline 4.90 & Disse & 4.75 \\
\hline 4.77 & Eryth & 4.75 \\
\hline 2.10 & Immuno & 3.48 \\
\hline 2.80 & Endo & 2.44 \\
\hline 1.40 & Stell & 1.98 \\
\hline 0.43 & Bile & 0.55 \\
\hline
\end{tabular}

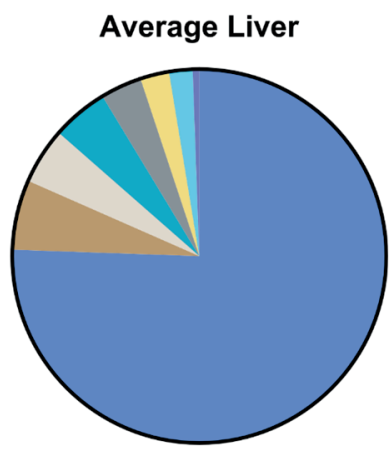

Figure 21. Proteomics-based deconvolution of human liver tissue using Linseed. Proteomes from 56 human liver samples were deconvoluted. The numbers in the pie chart on the left (values from the literature) are volumes corresponding to the content of each group. ${ }^{7}$ The pie chart to the right shows the average composition of the 56 deconvoluted human liver samples. The table in the middle shows the proportions of each deconvoluted group.

A few of the liver samples deviated in their deconvoluted proportions. Patient 23 had a high proportion of the group corresponding to immune cells. Blood samples collected at the time of surgery revealed that patient 23 had the highest values of all patients for interleukins, chemokines, and TNF- $\alpha$ (Figure 22). Interestingly, the patient had normal levels of C-reactive protein (CRP) and displayed no signs of inflammation during surgery. However, the patient had a history of weekly gallstone (cholestasis) attacks, and several of the immune response markers have been connected to cholestasis. ${ }^{149}$

Two other patients (39 and 44) showed a higher proportion of stellate cells. Stellate cells produce ECM proteins in the liver and surplus ECM leads to fibrogenesis. We therefore looked at the clinical, non-invasive FIB-4 scores meant to detect advanced fibrosis. ${ }^{150}$ Both of these patients showed values of 
FIB-4 that were inconclusive and no visible indications of fibrosis were observed during surgery. ${ }^{151}$ Therefore, the composition of ECM proteins in the proteomes was examined. Fibrillary collagen levels (collagens 1, 3, and 5) were much higher in these two patients with a higher proportion of stellate cells (Figure 22B). Disease progression from mild to moderate and then finally advanced fibrosis is associated with an increase in fibrillar collagens. ${ }^{152}$

Deconvolution of proteomics data could be a useful tool rather like a molecular microscope for revealing information on cellular composition and extracellular compartments. Tissues with altered cell type proportions were in agreement with clinical blood markers and disease markers in extracellular tissue. Deconvolution of proteomics data can possibly be used to identify disease markers and/or mechanisms in new proteomics data and in retrospective analysis of database-deposited proteomics data.
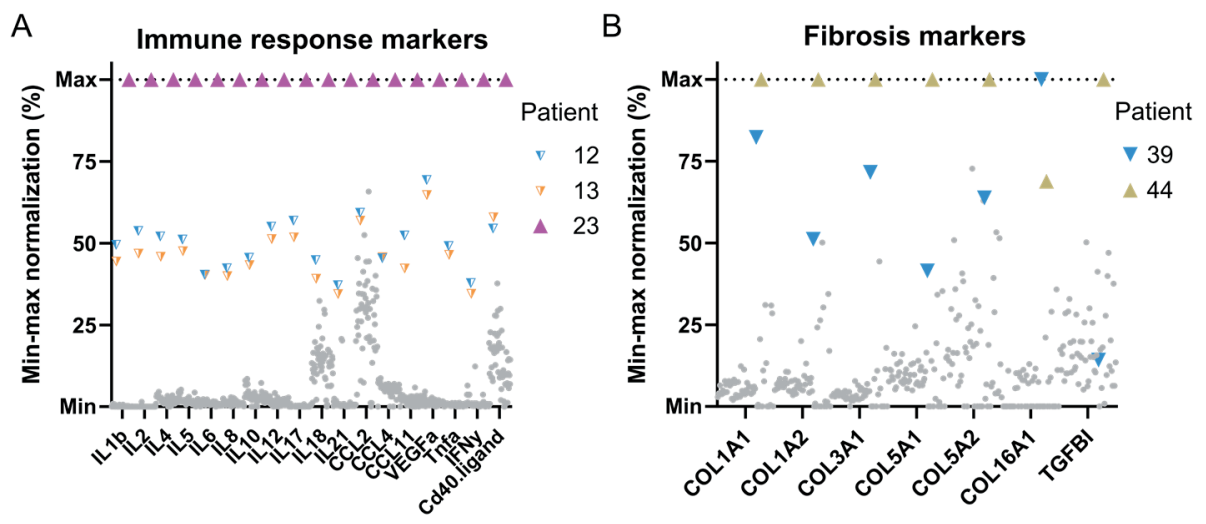

Figure 22. Investigation of livers with divergent proportions. A, Immune response markers measured from blood sample for the 56 patients. B, Fibrosis markers from the proteomics dataset. A,B, Coloured symbols are values of patients of interest, while grey symbols are values obtained from other patients. Deconvolution of the liver sample from patient 23 showed an increase in immune cells, and patients 39 and 44 showed elevated levels of stellate cells. 


\section{Conclusions}

This thesis is a proteomics-based investigation with the goal of better understanding inter-individual variability in liver tissue and variability in in vitro models used to study liver function. In particular, proteomics and functional informed analyses of liver-relevant ADME proteins provided explanations for the variability between in vitro models and in vivo hepatic drug disposition. Additionally, conditions for maintenance and optimization of primary human hepatocyte 2D and 3D cultures were established. Finally, deconvolution of global proteomics data from human liver tissue provided a useful tool that can be used as a molecular microscope for investigating cellular composition, extracellular compartments, and for exploring cell-type-specific events.

The conclusions of this thesis are summarized here:

- Explaining the inter-individual variability of important ADME proteins requires multi-omics approaches, because variation in protein expression cannot only be explained by genotype.

- Proteomics and functional analyses of isolated human hepatocytes revealed size-dependent characteristics similar to the differences observed between zones in the liver lobule.

- Proteomics-informed analyses of batch-to-batch variability in hepatocytes allowed us to develop an apoptosis inhibition protocol to restore hepatocyte function.

- Proteomics, functional, and biochemical analyses of human hepatocytes cultured in 3D spheroids revealed media-dependent differences in hepatic drug disposition studies, as well as that fasting glucose and insulin levels provide a more hepatocyte-like phenotype.

- High-throughput 3D cultured primary human hepatocytes can be used to quantify and visualise uptake of the model substrate ASP+ with accuracy similar to 2D monolayers.

- Deconvolution of proteomic datasets yields information on cell-type proportions in human liver tissue, and proteomic-based deconvolution can reveal information about extracellular compartments. Furthermore, changes in the deconvoluted cell-type proportions correlated with clinical markers from blood samples. 


\section{Populärvetenskaplig sammanfattning}

Under läkemedelsutvecklingsprocessen undersöks läkemedlets upptag, fördelning, nedbrytning, eliminering samt toxiska egenskaper. Många av dessa processer sker i levern. För att minimera behovet av djur- och människor studier kan studier av dessa egenskaper göras i laboratoriemiljö med hjälp av cellbaserade modeller som simulerar funktionen av levern, ofta används en mänskliga hepatocyter. Det finns många olika sätt att använda cellbaserade modeller av hepatocyter och de kommer med olika fördelar och nackdelar. Målet med denna avhandling var att undersöka, jämföra och förbättra cellbaserade modeller av hepatocyter och leverprover.

Först så mättes mängden av proteiner involverade i läkemedels fördelning i 149 lever prover. Analysen visade att vår arvsmassa inte kunde förklara variationen mellan proverna. Därför så undersöktes proteinet NTCP, som transporterar gallsyror och läkemedel, i detalj. Vi kunde se att miljöfaktorer, så som alkohol och rökning, och hur DNA läses av oberoende av DNA sekvensen, så kallad epigenetik, påverkar hur mycket NTCP som finns i levern.

Därefter så isolerades hepatocyter från mänsklig lever och förvarades i väldigt låga temperaturer, så kallad kryokonservering. Ett känt problem när man förvarar hepatocyter är att vissa av dessa celler kan ta skada och inte går att använda. Ett protokoll för att lindra den skada som skett utvecklades. Detta protokoll hjälpte även de celler som har svårt att bilda cell-cell kontakter.

Sedan så karakteriserades 3 dimensionell odling av hepatocyter. Karakteriseringen visade att olika odlingslösningar, som vanligtvis användes $i$ hepatocytodlingar, gav väldigt olika resultat med olika egenskaper på hepatocyter. Detta betyder att man får olika resultat i studier om man använder olika typer av odlingslösningar för hepatocyter. Genom att jämföra med nyligen isolerade hepatocyter kunde vi se att lösningar som har insulin samt sockernivåer liknande dem vi har i kroppen vid fasta gör att hepatocyter beter sig mer likt hur det gör i kroppen. Vi lyckades även utföra upptagsstudier av modelläkemedel, som vanligen görs i 2 dimensionella odlingar, i 3 dimensionella odlingar.

Slutligen undersöktes om man kan bestämma vilka celler, vad cellerna gör och hur stor del av cellerna som finns i vävnadsprover genom att mäta proteiner. Proportioner av olika celltyper från mänsklig lever kunde beräknas och stämde bra med värden som andra har sätt tidigare med hjälp av andra metoder. Förutom att beräkna proportioner av celltyper kunde även proportionen av vävnad som är utanför celler beräknas. Detta har inte observerats tidigare 
när man gjort beräkningarna med hjälp av mRNA. Leverprover som hade avvikande proportioner i jämförelse med de andra undersöktes vidare. Dessa prover kunde associeras med sjukdomsförlopp med hjälp av tester utförda på blodprover samt protein uttryck.

Sammanfattningsvis så bidrar denna avhandling till en ökad förståelse, förbättringar samt nya tillämpningsområden för laboratoriemodeller och vävnader som används under läkemedelsutvecklingsprocessen. 


\section{Acknowledgments}

The work presented in this thesis was carried out at the Department of Pharmacy, Faculty of Pharmacy, Uppsala University, Sweden. The studies were financially supported by the Swedish Research Council. I would like to thank IF:s stiftelse, Elisabeth och Alfred Ahlqvists stiftelse, C. R. Leffmans stiftelse and G. Bergmarks stiftelse for travel grants that allowed me to attend various courses and research conferences to present my work.

First, I would like to thank everyone that made this thesis possible and made going to work so enjoyable.

I would like to express my gratitude to my supervisors and co-supervisors:

Per Artursson, for giving me the opportunity to be scientifically curious and pursue the things we found interesting. Also, for the creative discussions resulting in new and stimulating ideas, even though there was not enough time to investigate all of them. As well as giving me the tools to wrap it all together into this thesis.

Mårten Fryknäs, for giving me new perspective and views on how to solve upcoming obstacles. For being a beacon of positive energy and for welcoming me into your lab and all the wonderful co-workers.

Tobias Sjöblom, for giving the opportunity to participate in interesting collaboration projects.

Peter Nygren, for helping out with the direction of the thesis project and giving your views on how to improve it.

I would like to thank all my co-authors and contributors; without you these studies would not have been possible. Jozef Urdzik, for all hard work and skill in our collaborative liver projects. My two amazing master students, Alina Meyer and Sarah McComas, for your excellent work, detailed analysis and great ideas. Jakob Rudfeldt, Kristin Blom och Frida Nyberg for showing me around our lab, helping with instruments and for all the fun we had in the lab. Tor Halle for your skillful immunohistochemical staining. Jens Eriksson for your patience and skills during the microscopy. Di Yuan for great ideas and skills in optimization. Jacek Wiśniewski for your expertise in global proteomics sample preparation. 
To my fellow past and present $\mathrm{PhD}$ students in the drug delivery group:

Evgeniya, for brightening up the day both in- and outside of the lab. It is really fun working with you and I think we complement each other in the lab quite well. Also, thanks for sharing your amazing drawing and cooking skills.

Magnus, for always having something new and interesting to discuss and for sharing your engineering skills on how to build the best sandwich for torsdagsfika. I am amazed by the sheer volume of knowledge that you possess, and it makes it very interesting to discuss and work with you.

Andrea, for sharing your musical passion both at work and outside work. It was always wonderful to hear you play.

Christine, for bringing some order into the otherwise fairly chaotic environment, and for being the one introducing me to the lab and the work environment.

André, for introducing me to all the hidden secrets of BMC and its surroundings.

Signe, for bringing so much energy to our lab. I also enjoyed having someone to talk in-depth statistics and big data analysis with.

Merve, for reigniting the social aspects at work and outside of work when COVID allowed it.

Rebekkah, even though you recently started your PhD studies, you are part of the future of this group and I am convinced it will be safe hands.

Thanks to all the past and present members of the drug delivery group for making it what it is today. A special thanks to Elin, Maria M. and Rezvan for taking care of and organizing the lab. To Maria K. and Patrik L. for always having your doors open for discussions and questions, and for sharing your knowledge. Varun, for taking on much responsibility and helping out in every way possible. Also for sharing the amazing experience of jumping out of a plane. To Fabienne for showing me the ropes. To the past and present members of UDOPP for your great expertise and industrial knowledge. To Aljona for all the support with LC and MS. To Richard for your molecular and chemistry expertise and amazing taste in music. To Shibu for helping out during long experiments and being a great friend outside of work. To all the members of the Bergström group for making the lab an interesting and fun place. To Caroline and Oliver for the time we spent as office buddies. To Albin, Tomás and Jamal for all the tennis matches. To Patrik D.S. for our physics talks and nerdy after-works. To all $\mathrm{PhD}$ students in the old and new department of Pharmacy for creating a fun work environment with $\mathrm{PhD}$ student days, after-works and lunch discussions.

To family and friends that supported me and stimulated my nerdy side. To my mother for sitting down and giving me the time I needed for school. To my father for inspiring me to also take breaks and not always focus on work. To 
my sisters for always helping and supporting me, and keeping the family together. To Maddox for brightening up my day every time I think of you. To Sebastian and Alex for all the nerdy talks and late nights. To my wonderful Emelie for supporting me during the writing of this thesis, dealing with all my craziness and making me the luckiest man on the planet. To Melvin and Milton for making sure I take breaks. 


\section{References}

1. Polidoro, M. A., Ferrari, E., Marzorati, S., Lleo, A. \& Rasponi, M. Experimental liver models: From cell culture techniques to microfluidic organs-on-chip. Liver Int. 41, 1744-1761 (2021).

2. Aebersold, R. \& Mann, M. Mass-spectrometric exploration of proteome structure and function. Nature 537, 347-355 (2016).

3. Schröder A et al. Genomics of ADME Gene Expression: Mapping Expression Quantitative Trait Loci Relevant for Absorption, Distribution, Metabolism and Excretion of Drugs in Human Liver. The pharmacogenomics journal (2013). doi:10.1038/tpj.2011.44

4. Kan, Z. \& Madoff, D. C. Liver Anatomy: Microcirculation of the Liver. Semin. Interv. Radiol. 25, 77-85 (2008).

5. Pond, S. M. \& Tozer, T. N. First-Pass Elimination Basic Concepts and Clinical Consequences. Clin. Pharmacokinet. 9, 1-25 (1984).

6. LeCluyse, E. L., Witek, R. P., Andersen, M. E. \& Powers, M. J. Organotypic liver culture models: Meeting current challenges in toxicity testing. Crit. Rev. Toxicol. 42, 501-548 (2012).

7. Bogdanos, D. P., Gao, B. \& Gershwin, M. E. Liver Immunology. Compr. Physiol. 3, 567-598 (2013).

8. Kmieć, Z. Cooperation of liver cells in health and disease. Adv. Anat. Embryol. Cell Biol. 161, III-XIII, 1-151 (2001).

9. Trefts, E., Gannon, M. \& Wasserman, D. H. The liver. Curr. Biol. CB 27, R1147-R1151 (2017).

10. Kietzmann, T. Metabolic zonation of the liver: The oxygen gradient revisited. Redox Biol. 11, 622-630 (2017).

11. Turner, R. et al. Human hepatic stem cell and maturational liver lineage biology. Hepatology 53, 1035-1045 (2011).

12. Wang, M.-J., Chen, F., Lau, J. T. Y. \& Hu, Y.-P. Hepatocyte polyploidization and its association with pathophysiological processes. Cell Death Dis. 8, e2805 (2017).

13. Gebhardt, R. \& Matz-Soja, M. Liver zonation: Novel aspects of its regulation and its impact on homeostasis. World J. Gastroenterol. WJG 20, 8491-8504 (2014).

14. Lindros, K. O. Zonation of cytochrome P450 expression, drug metabolism and toxicity in liver. Gen. Pharmacol. Vasc. Syst. 28, 191-196 (1997).

15. MacParland, S. A. et al. Single cell RNA sequencing of human liver reveals distinct intrahepatic macrophage populations. Nat. Commun. 9, 4383 (2018).

16. Jungermann, K. \& Kietzmann, T. Oxygen: Modulator of metabolic zonation and disease of the liver. Hepatology 31, 255-260 (2000).

17. Gebhardt, R. \& Hovhannisyan, A. Organ patterning in the adult stage: The role of Wnt/ $\beta$-catenin signaling in liver zonation and beyond. Dev. Dyn. 239, 45-55 (2010). 
18. Matz-Soja, M., Hovhannisyan, A. \& Gebhardt, R. Hedgehog signalling pathway in adult liver: A major new player in hepatocyte metabolism and zonation? Med. Hypotheses 80, 589-594 (2013).

19. Rowe, C. et al. Proteome-wide analyses of human hepatocytes during differentiation and dedifferentiation. Hepatology 58, 799-809 (2013).

20. Lauschke, V. M. et al. Massive rearrangements of cellular MicroRNA signatures are key drivers of hepatocyte dedifferentiation. Hepatology 64, 1743-1756 (2016).

21. Greetje, E. et al. Molecular Mechanisms Underlying the Dedifferentiation Process of Isolated Hepatocytes and Their Cultures. Curr. Drug Metab. 7, 629-660 (2006).

22. Bell, C. C. et al. Comparison of hepatic 2D sandwich cultures and 3D spheroids for long-term toxicity applications: A multi-center study. Toxicol. Sci. (2018). doi:10.1093/toxsci/kfx289

23. Bell, C. C. et al. Characterization of primary human hepatocyte spheroids as a model system for drug-induced liver injury, liver function and disease. Sci. Rep. 6, srep25187 (2016).

24. Tostões, R. M. et al. Human liver cell spheroids in extended perfusion bioreactor culture for repeated-dose drug testing. Hepatology 55, 1227-1236 (2012).

25. Braet, F. \& Wisse, E. Structural and functional aspects of liver sinusoidal endothelial cell fenestrae: a review. Comp. Hepatol. 1, 1 (2002).

26. Sørensen, K. K., Simon-Santamaria, J., McCuskey, R. S. \& Smedsrød, B. Liver Sinusoidal Endothelial Cells. in Comprehensive Physiology 1751-1774 (American Cancer Society, 2015). doi:10.1002/cphy.c140078

27. Nedredal, G. I. et al. Significant contribution of liver nonparenchymal cells to metabolism of ammonia and lactate and cocultivation augments the functions of a bioartificial liver. Am. J. Physiol.-Gastrointest. Liver Physiol. 293, G75-G83 (2007).

28. Smedsrød, B. Cellular events in the uptake and degradation of hyaluronan. $A d v$. Drug Deliv. Rev. 7, 265-278 (1991).

29. Hellerbrand, C. Hepatic stellate cells - the pericytes in the liver. Pflüg. Arch. Eur. J. Physiol. 465, 775-778 (2013).

30. Higashi, T., Friedman, S. L. \& Hoshida, Y. Hepatic stellate cells as key target in liver fibrosis. Adv. Drug Deliv. Rev. 121, 27-42 (2017).

31. Bilzer, M., Roggel, F. \& Gerbes, A. L. Role of Kupffer cells in host defense and liver disease. Liver Int. 26, 1175-1186 (2006).

32. Kolios, G., Valatas, V. \& Kouroumalis, E. Role of Kupffer cells in the pathogenesis of liver disease. World J. Gastroenterol. 12, 7413-7420 (2006).

33. Broadley, S. P. et al. Dual-Track Clearance of Circulating Bacteria Balances Rapid Restoration of Blood Sterility with Induction of Adaptive Immunity. Cell Host Microbe 20, 36-48 (2016).

34. Zeng, Z. et al. CRIg Functions as a Macrophage Pattern Recognition Receptor to Directly Bind and Capture Blood-Borne Gram-Positive Bacteria. Cell Host Microbe 20, 99-106 (2016).

35. Seki, E. \& Schwabe, R. F. Hepatic inflammation and fibrosis: Functional links and key pathways. Hepatology 61, 1066-1079 (2015).

36. Duffield, J. S. et al. Selective depletion of macrophages reveals distinct, opposing roles during liver injury and repair. J. Clin. Invest. 115, 56-65 (2005).

37. Pellicoro, A., Ramachandran, P., Iredale, J. P. \& Fallowfield, J. A. Liver fibrosis and repair: immune regulation of wound healing in a solid organ. Nat. Rev. Immunol. 14, 181-194 (2014). 
38. Tornio, A., Filppula, A. M., Niemi, M. \& Backman, J. T. Clinical Studies on Drug-Drug Interactions Involving Metabolism and Transport: Methodology, Pitfalls, and Interpretation. Clin. Pharmacol. Ther. 105, 1345-1361 (2019).

39. Zamek $\square$ Gliszczynski, M. J. et al. Transporters in Drug Development: 2018 ITC Recommendations for Transporters of Emerging Clinical Importance. Clin. Pharmacol. Ther. 104, 890-899 (2018).

40. Zanger, U. M. \& Schwab, M. Cytochrome P450 enzymes in drug metabolism: Regulation of gene expression, enzyme activities, and impact of genetic variation. Pharmacol. Ther. 138, 103-141 (2013).

41. Williams, J. A. et al. Drug-drug interactions for UDP-glucuronosyltransferase substrates: a pharmacokinetic explanation for typically observed low exposure (AUCi/AUC) ratios. Drug Metab. Dispos. 32, 1201-1208 (2004).

42. Cocucci, E., Kim, J. Y., Bai, Y. \& Pabla, N. Role of Passive Diffusion, Transporters, and Membrane Trafficking-Mediated Processes in Cellular Drug Transport. Clin. Pharmacol. Ther. 101, 121-129 (2017).

43. Nigam, S. K. What do drug transporters really do? Nat. Rev. Drug Discov. 14, 29-44 (2015).

44. Dean, M., Rzhetsky, A. \& Allikmets, R. The Human ATP-Binding Cassette (ABC) Transporter Superfamily. Genome Res. 11, 1156-1166 (2001).

45. Lin, L., Yee, S. W., Kim, R. B. \& Giacomini, K. M. SLC transporters as therapeutic targets: emerging opportunities. Nat. Rev. Drug Discov. 14, 543-560 (2015).

46. O'Hagan, S., Wright Muelas, M., Day, P. J., Lundberg, E. \& Kell, D. B. GeneGini: Assessment via the Gini Coefficient of Reference 'Housekeeping' Genes and Diverse Human Transporter Expression Profiles. Cell Syst. 6, 230-244.e1 (2018).

47. Li, J. \& Zhu, H.-J. Liquid Chromatography-Tandem Mass Spectrometry (LCMS/MS)-Based Proteomics of Drug-Metabolizing Enzymes and Transporters. Molecules 25, 2718 (2020).

48. Km, G. et al. Membrane transporters in drug development. Nat. Rev. Drug Discov. 9, (2010).

49. Brian, W. et al. Assessment of drug metabolism enzyme and transporter pharmacogenetics in drug discovery and early development: perspectives of the IPWG. Pharmacogenomics 17, 615-631 (2016).

50. Z, Z. \& W, T. Drug metabolism in drug discovery and development. Acta Pharm. Sin. B 8, (2018).

51. Iyanagi, T. Molecular Mechanism of Phase I and Phase II Drug $\square$ Metabolizing Enzymes: Implications for Detoxification. in International Review of Cytology 260, 35-112 (Academic Press, 2007).

52. Bleibel, W., Kim, S., D’Silva, K. \& Lemmer, E. R. Drug-Induced Liver Injury: Review Article. Dig. Dis. Sci. 52, 2463-2471 (2007).

53. Wm, L. Drug-induced hepatotoxicity. N. Engl. J. Med. 349, (2003).

54. Mosedale, M. \& Watkins, P. B. Drug-induced liver injury: Advances in mechanistic understanding that will inform risk management. Clin. Pharmacol. Ther. 101, 469-480 (2017).

55. Fontana, R. J. Pathogenesis of Idiosyncratic Drug-Induced Liver Injury and Clinical Perspectives. Gastroenterology 146, 914-928 (2014).

56. K, Z., N, F., G, D., D, S. \& F, K. Cell sources for in vitro human liver cell culture models. Exp. Biol. Med. Maywood NJ 241, (2016).

57. Rl, S.-Y. et al. A multicenter assessment of single-cell models aligned to standard measures of cell health for prediction of acute hepatotoxicity. Arch. Toxicol. 91, (2017). 
58. X, S., M, N. \& Em, S. Hepatocyte cryopreservation: is it time to change the strategy? World J. Gastroenterol. 16, (2010).

59. Hewitt, N. J. Optimisation of the Cryopreservation of Primary Hepatocytes. in Hepatocytes: Methods and Protocols (ed. Maurel, P.) 83-105 (Humana Press, 2010). doi:10.1007/978-1-60761-688-7_4

60. Alexandre, E. et al. Plateable cryopreserved human hepatocytes for the assessment of cytochrome P450 inducibility: experimental condition-related variables affecting their response to inducers. Xenobiotica 42, 968-979 (2012).

61. E, A. et al. Cryopreservation of adult human hepatocytes obtained from resected liver biopsies. Cryobiology 44, (2002).

62. Dunn, J. C. Y., Tompkins, R. G. \& Yarmush, M. L. Long-Term in Vitro Function of Adult Hepatocytes in a Collagen Sandwich Configuration. Biotechnol. Prog. 7, 237-245 (1991).

63. Lauschke, V. M., Shafagh, R. Z., Hendriks, D. F. G. \& Ingelman $\square$ Sundberg, M. 3D Primary Hepatocyte Culture Systems for Analyses of Liver Diseases, Drug Metabolism, and Toxicity: Emerging Culture Paradigms and Applications. Biotechnol. J. 0, 1800347

64. Messner, S., Agarkova, I., Moritz, W. \& Kelm, J. M. Multi-cell type human liver microtissues for hepatotoxicity testing. Arch. Toxicol. 87, 209-213 (2013).

65. Landry, J., Bernier, D., Ouellet, C., Goyette, R. \& Marceau, N. Spheroidal aggregate culture of rat liver cells: histotypic reorganization, biomatrix deposition, and maintenance of functional activities. J. Cell Biol. 101, 914-923 (1985).

66. Vorrink, S. U. et al. Endogenous and xenobiotic metabolic stability of primary human hepatocytes in long-term 3D spheroid cultures revealed by a combination of targeted and untargeted metabolomics. FASEB J. 31, 2696-2708 (2017).

67. Buesch, S., Schroeder, J., Bunger, M., D’Souza, T. \& Stosik, M. A Novel In Vitro Liver Cell Culture Flow System Allowing Long-Term Metabolism and Hepatotoxicity Studies. Appl. Vitro Toxicol. 4, 232-237 (2018).

68. Forsythe, S. D. et al. Environmental Toxin Screening Using Human-Derived 3D Bioengineered Liver and Cardiac Organoids. Front. Public Health 6, (2018).

69. Williams, G. M., Weisburger, E. K. \& Weisburger, J. H. Isolation and long-term cell culture of epithelial-like cells from rat liver. Exp. Cell Res. 69, 106-112 (1971).

70. Kozyra, M. et al. Human hepatic 3D spheroids as a model for steatosis and insulin resistance. Sci. Rep. 8, 14297 (2018).

71. Davidson, M. D., Ballinger, K. R. \& Khetani, S. R. Long-term exposure to abnormal glucose levels alters drug metabolism pathways and insulin sensitivity in primary human hepatocytes. Sci. Rep. 6, 28178 (2016).

72. Gu, C., Li, P., Liu, W., Zhou, Y. \& Tan, W.-S. The role of insulin in transdifferentiated hepatocyte proliferation and function in serum-free medium. J. Cell. Mol. Med. 23, 4165-4178 (2019).

73. Griffiths, J. A Brief History of Mass Spectrometry. Anal. Chem. 80, 5678-5683 (2008).

74. Eliuk, S. \& Makarov, A. Evolution of Orbitrap Mass Spectrometry Instrumentation. Annu. Rev. Anal. Chem. 8, 61-80 (2015).

75. Yates, J. R., Ruse, C. I. \& Nakorchevsky, A. Proteomics by Mass Spectrometry: Approaches, Advances, and Applications. Annu. Rev. Biomed. Eng. 11, 49-79 (2009).

76. Goldberg, S. Mechanical/Physical Methods of Cell Disruption and Tissue Homogenization. in 2D PAGE: Sample Preparation and Fractionation (ed. Posch, A.) 3-22 (Humana Press, 2008). doi:10.1007/978-1-60327-064-9_1 
77. Rogers, J. C. \& Bomgarden, R. D. Sample Preparation for Mass SpectrometryBased Proteomics; from Proteomes to Peptides. in Modern Proteomics - Sample Preparation, Analysis and Practical Applications (eds. Mirzaei, H. \& Carrasco, M.) 43-62 (Springer International Publishing, 2016).

78. Tm, A. Ion suppression in mass spectrometry. Clin. Chem. 49, (2003).

79. Wiśniewski, J. R., Zougman, A., Nagaraj, N. \& Mann, M. Universal sample preparation method for proteome analysis. Nat. Methods 6, 359-362 (2009).

80. Y, H. et al. Statistical characterization of the charge state and residue dependence of low-energy CID peptide dissociation patterns. Anal. Chem. 77, (2005).

81. Dongré, A. R., Jones, J. L., Somogyi, Á. \& Wysocki, V. H. Influence of Peptide Composition, Gas-Phase Basicity, and Chemical Modification on Fragmentation Efficiency: Evidence for the Mobile Proton Model. J. Am. Chem. Soc. 118, 8365-8374 (1996).

82. Jv, O., Se, O. \& M, M. Trypsin cleaves exclusively C-terminal to arginine and lysine residues. Mol. Cell. Proteomics MCP 3, (2004).

83. Wiśniewski, J. R. \& Rakus, D. Multi-enzyme digestion FASP and the 'Total Protein Approach'-based absolute quantification of the Escherichia coli proteome. J. Proteomics 109, 322-331 (2014).

84. Dau, T., Bartolomucci, G. \& Rappsilber, J. Proteomics Using Protease Alternatives to Trypsin Benefits from Sequential Digestion with Trypsin. Anal. Chem. 92, 9523-9527 (2020).

85. Kulak, N. A., Geyer, P. E. \& Mann, M. Loss-less Nano-fractionator for High Sensitivity, High Coverage Proteomics. Mol. Cell. Proteomics MCP 16, 694705 (2017).

86. Branca, R. M. M. et al. HiRIEF LC-MS enables deep proteome coverage and unbiased proteogenomics. Nat. Methods 11, 59-62 (2014).

87. Vidova, V. \& Spacil, Z. A review on mass spectrometry-based quantitative proteomics: Targeted and data independent acquisition. Anal. Chim. Acta 964, 7-23 (2017).

88. Scott, K. B., Turko, I. V. \& Phinney, K. W. Chapter Eleven - QconCAT: Internal Standard for Protein Quantification. in Methods in Enzymology (ed. Kelman, Z.) 566, 289-303 (Academic Press, 2016).

89. Rowland, M., Peck, C. \& Tucker, G. Physiologically-Based Pharmacokinetics in Drug Development and Regulatory Science. Annu. Rev. Pharmacol. Toxicol. 51, 45-73 (2011).

90. Zhuang, X. \& Lu, C. PBPK modeling and simulation in drug research and development. Acta Pharm. Sin. B 6, 430-440 (2016).

91. Wiśniewski, J. R. Dilemmas With Absolute Quantification of Pharmacologically Relevant Proteins Using Mass Spectrometry. J. Pharm. Sci. 110, 17-21 (2021).

92. Domon, B. \& Aebersold, R. Options and considerations when selecting a quantitative proteomics strategy. Nat. Biotechnol. 28, 710-721 (2010).

93. Wegler, C. et al. Variability in Mass Spectrometry-based Quantification of Clinically Relevant Drug Transporters and Drug Metabolizing Enzymes. Mol. Pharm. (2017). doi:10.1021/acs.molpharmaceut.7b00364

94. Koopmans, F., Ho, J. T. C., Smit, A. B. \& Li, K. W. Comparative Analyses of Data Independent Acquisition Mass Spectrometric Approaches: DIA, WiSIMDIA, and Untargeted DIA. PROTEOMICS 18, 1700304 (2018).

95. Monti, C., Zilocchi, M., Colugnat, I. \& Alberio, T. Proteomics turns functional. J. Proteomics 198, 36-44 (2019).

96. García-Campos, M. A., Espinal-Enríquez, J. \& Hernández-Lemus, E. Pathway Analysis: State of the Art. Front. Physiol. 6, (2015). 
97. Jassal, B. et al. The reactome pathway knowledgebase. Nucleic Acids Res. 48, D498-D503 (2020).

98. Ogata, H. et al. KEGG: Kyoto Encyclopedia of Genes and Genomes. Nucleic Acids Res. 27, 29-34 (1999).

99. Mi, H., Muruganujan, A., Ebert, D., Huang, X. \& Thomas, P. D. PANTHER version 14: more genomes, a new PANTHER GO-slim and improvements in enrichment analysis tools. Nucleic Acids Res. 47, D419-D426 (2019).

100. Carbon, S. et al. AmiGO: online access to ontology and annotation data. Bioinformatics 25, 288-289 (2009).

101. Giladi, A. \& Amit, I. Immunology, one cell at a time. Nat. News 547, 27 (2017).

102. Regev, A. et al. The Human Cell Atlas. eLife 6, e27041 (2017).

103. Lapuente-Santana, Ó. \& Eduati, F. Toward Systems Biomarkers of Response to Immune Checkpoint Blockers. Front. Oncol. 10, (2020).

104. Sharma, A. et al. Non-genetic intra-tumor heterogeneity is a major predictor of phenotypic heterogeneity and ongoing evolutionary dynamics in lung tumors. bioRxiv 698845 (2019). doi:10.1101/698845

105. Elloumi, F. et al. Systematic Bias in Genomic Classification Due to Contaminating Non-neoplastic Tissue in Breast Tumor Samples. BMC Med. Genomics 4, 54 (2011).

106. Manzoni, C. et al. Genome, transcriptome and proteome: the rise of omics data and their integration in biomedical sciences. Brief. Bioinform. 19, 286-302 (2018).

107. Wang, D. et al. A deep proteome and transcriptome abundance atlas of 29 healthy human tissues. Mol. Syst. Biol. 15, e8503 (2019).

108. Cox, J. \& Mann, M. MaxQuant enables high peptide identification rates, individualized p.p.b.-range mass accuracies and proteome-wide protein quantification. Nat. Biotechnol. 26, nbt.1511 (2008).

109. Tyanova, S. et al. The Perseus computational platform for comprehensive analysis of (prote)omics data. Nat. Methods 13, 731-740 (2016).

110. Thomas, P. D. et al. PANTHER: A Library of Protein Families and Subfamilies Indexed by Function. Genome Res. 13, 2129-2141 (2003).

111. Huang, D. W., Sherman, B. T. \& Lempicki, R. A. Bioinformatics enrichment tools: paths toward the comprehensive functional analysis of large gene lists. Nucleic Acids Res. 37, 1-13 (2009).

112. Rueden, C. T. et al. ImageJ2: ImageJ for the next generation of scientific image data. BMC Bioinformatics 18, 529 (2017).

113. The UniProt Consortium. UniProt: the universal protein knowledgebase in 2021. Nucleic Acids Res. 49, D480-D489 (2021).

114. Uhlén, M. et al. Tissue-based map of the human proteome. Science 347, (2015).

115. Bielow, C., Mastrobuoni, G. \& Kempa, S. Proteomics Quality Control: Quality Control Software for MaxQuant Results. J. Proteome Res. 15, 777-787 (2016).

116. Chambers, M. C. et al. A cross-platform toolkit for mass spectrometry and proteomics. Nat. Biotechnol. 30, 918-920 (2012).

117. LeCluyse, E. L. \& Alexandre, E. Isolation and Culture of Primary Hepatocytes from Resected Human Liver Tissue. in Hepatocytes: Methods and Protocols (ed. Maurel, P.) 57-82 (Humana Press, 2010). doi:10.1007/978-1-60761-688-7_3

118. Kim, D.-S. et al. A liver-specific gene expression panel predicts the differentiation status of in vitro hepatocyte models. Hepatology 66, 1662-1674 (2017).

119. Vorrink, S. U., Zhou, Y., Ingelman-Sundberg, M. \& Lauschke, V. M. Prediction of Drug-Induced Hepatotoxicity Using Long-Term Stable Primary Hepatic 3D Spheroid Cultures in Chemically Defined Conditions. Toxicol. Sci. 163, 655665 (2018). 
120. Ahlin, G. et al. Structural Requirements for Drug Inhibition of the Liver Specific Human Organic Cation Transport Protein 1. J. Med. Chem. 51, 5932-5942 (2008).

121. Wang, X., Park, J., Susztak, K., Zhang, N. R. \& Li, M. Bulk tissue cell type deconvolution with multi-subject single-cell expression reference. Nat. Commun. 10, (2019).

122. Zaitsev, K., Bambouskova, M., Swain, A. \& Artyomov, M. N. Complete deconvolution of cellular mixtures based on linearity of transcriptional signatures. Nat. Commun. 10, 2209 (2019).

123. Aebersold, R., Burlingame, A. L. \& Bradshaw, R. A. Western Blots versus Selected Reaction Monitoring Assays: Time to Turn the Tables? Mol. Cell. Proteomics MCP 12, 2381-2382 (2013).

124. Lloyd, J. T. \& Glass, K. C. Biological function and histone recognition of family IV bromodomain-containing proteins. J. Cell. Physiol. 233, 1877-1886 (2018).

125. Lever, M. \& Slow, S. The clinical significance of betaine, an osmolyte with a key role in methyl group metabolism. Clin. Biochem. 43, 732-744 (2010).

126. Foster, A. J. et al. Integrated in vitro models for hepatic safety and metabolism: evaluation of a human Liver-Chip and liver spheroid. Arch. Toxicol. 93, 10211037 (2019).

127. Arakawa, H. et al. Preliminary Evaluation of Three-Dimensional Primary Human Hepatocyte Culture System for Assay of Drug-Metabolizing Enzyme-Inducing Potential. Biol. Pharm. Bull. 40, 967-974 (2017).

128. Arrigoni, O. \& De Tullio, M. C. Ascorbic acid: much more than just an antioxidant. Biochim. Biophys. Acta BBA - Gen. Subj. 1569, 1-9 (2002).

129. Parker, W. H., Qu, Z. \& May, J. M. Intracellular Ascorbate Prevents Endothelial Barrier Permeabilization by Thrombin. J. Biol. Chem. 290, 21486-21497 (2015).

130. Parker, W. H., Rhea, E. M., Qu, Z.-C., Hecker, M. R. \& May, J. M. Intracellular ascorbate tightens the endothelial permeability barrier through Epac1 and the tubulin cytoskeleton. Am. J. Physiol. - Cell Physiol. 311, C652-C662 (2016).

131. Yuan, Y., Hilliard, G., Ferguson, T. \& Millhorn, D. E. Cobalt Inhibits the Interaction between Hypoxia-inducible Factor- $\alpha$ and von Hippel-Lindau Protein by Direct Binding to Hypoxia-inducible Factor- $\alpha^{*}$. J. Biol. Chem. 278, 1591115916 (2003).

132. Oliva $\square$ Vilarnau, N., Vorrink, S. U., Ingelman $\square$ Sundberg, M. \& Lauschke, V. M. A 3D Cell Culture Model Identifies Wnt/ $\beta \square$ Catenin Mediated Inhibition of p53 as a Critical Step during Human Hepatocyte Regeneration. Adv. Sci. 7, (2020).

133. Ölander, M., Wiśniewski, J. R. \& Artursson, P. Cell-type-resolved proteomic analysis of the human liver. Liver Int. 40, 1770-1780 (2020).

134. Vildhede, A., Wiśniewski, J. R., Norén, A., Karlgren, M. \& Artursson, P. Comparative Proteomic Analysis of Human Liver Tissue and Isolated Hepatocytes with a Focus on Proteins Determining Drug Exposure. J. Proteome Res. 14, 3305-3314 (2015).

135. Neve, E. P. A., Artursson, P., Ingelman-Sundberg, M. \& Karlgren, M. An Integrated in Vitro Model for Simultaneous Assessment of Drug Uptake, Metabolism, and Efflux. Mol. Pharm. 10, 3152-3163 (2013).

136. Wegler, C. et al. Proteomics-Informed Prediction of Rosuvastatin Plasma Profiles in Patients with a Wide Range of Body Weight. Clin. Pharmacol. Ther. n/a, (2021). 
137. Fattah, S. et al. Inter-Subject Variability in OCT1 Activity in 27 Batches of Cryopreserved Human Hepatocytes and Association with OCT1 mRNA Expression and Genotype. Pharm. Res. 34, 1309-1319 (2017).

138. Ito, S. et al. Competitive Inhibition of the Luminal Efflux by Multidrug and Toxin Extrusions, but Not Basolateral Uptake by Organic Cation Transporter 2, Is the Likely Mechanism Underlying the Pharmacokinetic Drug-Drug Interactions Caused by Cimetidine in the Kidney. J. Pharmacol. Exp. Ther. 340, 393403 (2012).

139. Massmann, V. et al. The organic cation transporter 3 (OCT3) as molecular target of psychotropic drugs: transport characteristics and acute regulation of cloned murine OCT3. Pflüg. Arch. - Eur. J. Physiol. 466, 517-527 (2014).

140. Ahlin, G. et al. Genotype-dependent effects of inhibitors of the organic cation transporter, OCT1: predictions of metformin interactions. Pharmacogenomics J. 11, 400-411 (2011).

141. Jinakote, M. et al. High affinity of 4-(4-(dimethylamino)styryl)-N-methylpyridinium transport for assessing organic cation drugs in hepatocellular carcinoma cells. Fundam. Clin. Pharmacol. 34, 365-379 (2020).

142. Salomon, J. J. et al. Transport of the fluorescent organic cation 4-(4-(dimethylamino)styryl)-N-methylpyridinium iodide (ASP+) in human respiratory epithelial cells. Eur. J. Pharm. Biopharm. 81, 351-359 (2012).

143. Jahn, K. A., Biazik, J. M. \& Braet, F. GM1 Expression in Caco-2 Cells: Characterisation of a Fundamental Passage-dependent Transformation of a Cell Line. J. Pharm. Sci. 100, 3751-3762 (2011).

144. Mateus, A., Matsson, P. \& Artursson, P. Rapid Measurement of Intracellular Unbound Drug Concentrations. Mol. Pharm. 10, 2467-2478 (2013).

145. Jiang, R., Shen, H. \& Piao, Y.-J. The morphometrical analysis on the ultrastructure of A549 cells. Romanian J. Morphol. Embryol. Rev. Roum. Morphol. Embryol. 51, 663-667 (2010).

146. Milo, R. What is the total number of protein molecules per cell volume? A call to rethink some published values. BioEssays 35, 1050-1055 (2013).

147. Treyer, A. et al. Intracellular Drug Bioavailability: Effect of Neutral Lipids and Phospholipids. Mol. Pharm. 15, 2224-2233 (2018).

148. Hjelmesæth, J. et al. Impact of body weight, low energy diet and gastric bypass on drug bioavailability, cardiovascular risk factors and metabolic biomarkers: protocol for an open, non-randomised, three-armed single centre study (COCKTAIL). BMJ Open 8, (2018).

149. Li, M., Cai, S.-Y. \& Boyer, J. L. Mechanisms of bile acid mediated inflammation in the liver. Mol. Aspects Med. 56, 45-53 (2017).

150. Sterling, R. K. et al. Development of a simple noninvasive index to predict significant fibrosis in patients with HIV/HCV coinfection. Hepatology 43, 13171325 (2006)

151. Younossi, Z. M. et al. Role of Noninvasive Tests in Clinical Gastroenterology Practices to Identify Patients With Nonalcoholic Steatohepatitis at High Risk of Adverse Outcomes: Expert Panel Recommendations. Off. J. Am. Coll. Gastroenterol. ACG 116, 254-262 (2021).

152. Karsdal, M. A. et al. The good and the bad collagens of fibrosis - Their role in signaling and organ function. Adv. Drug Deliv. Rev. 121, 43-56 (2017). 


\section{Acta Universitatis Upsaliensis}

Digital Comprehensive Summaries of Uppsala Dissertations from the Faculty of Pharmacy 298

Editor: The Dean of the Faculty of Pharmacy

A doctoral dissertation from the Faculty of Pharmacy, Uppsala University, is usually a summary of a number of papers. A few copies of the complete dissertation are kept at major Swedish research libraries, while the summary alone is distributed internationally through the series Digital Comprehensive Summaries of Uppsala Dissertations from the Faculty of Pharmacy. (Prior to January, 2005, the series was published under the title "Comprehensive Summaries of Uppsala Dissertations from the Faculty of Pharmacy".) 